\title{
The Korean Early Palaeolithic: Patterns and Identities
}

\author{
$\mathbf{\Delta} \cdot \boldsymbol{\Delta} \cdot \mathbf{\Delta}$ \\ HYEONG WOO LEE
}

\section{INTRODUCTION}

The oldest Palaeolithic materials in East Asia were Discovered During eXCAVATIONS at the site of Chongokni (Jeongokri) in the late 1970s (RICP 1983). Although efforts were made to strengthen identification of these materials as "Palaeolithic," and specifically to emphasize correspondences with newly discovered Palaeolithic finds (i.e., "Acheulean hand axes") elsewhere, the growing corpus of Palaeolithic information in the succeeding decades has driven research in alternative directions. Newer Palaeolithic data have led to corrections of former analyses of these finds and the abandonment of conventional theoretical frameworks based on European archaeology.

The goals of academic studies of the early occupation of Korea have increasingly varied since the original discoveries were made in the 1970s. Even painstaking, longterm research did not result in adequate evaluation and refinement of the original rough chronology for the Palaeolithic in the region. Extensive radiometric analyses contradict the initial chronology. Lithic assemblages that were originally claimed to have strong morphological and typological affinities to Western Old World assemblages are now being reexamined.

Until the 1980s, the paucity of collected archaeological data hampered interpretations, but accumulating evidence from Korea now contradicts conservative models based on data obtained outside Korea. Over the past 20 years, however, a great deal of new material evidence has been discovered. These archaeological finds are raising numerous questions and previously solid interpretations of earlier finds are being revisited. In particular, the comparative use of Western chronologies is being challenged. The term "Middle Palaeolithic," drawn from European Palaeolithic studies, is now often rejected in Korea. There is a growing consensus regarding the absence of significant Middle Palaeolithic cultural traits during the Korean Palaeolithic. Thus, the early Palaeolithic period in Korea occurs from some time in the middle Pleistocene until c. 40,000-30,000 years ago. Rather than refer to this period as the "Lower Palaeolithic," following a traditional three-stage model (Lower, Middle, Upper), the term Early Palaeolithic is frequently adopted, using a two-stage (Early and Late) model (Bae and Bae 2012; Seong 2011). 
Another traditional assumption was that crudely made core tools represented the initial occupation of Korea. Like the Oldowan and Clactonian, the simple manufacture of the Korean toolkit was considered a distinct cultural tradition preceding hand axe-bearing assemblages. However, growing collections accumulating over the last 20 years have suggested that a model of unilinear progress is not appropriate (see the major sites and lithic examples in Figures 1 and 2). It is necessary to examine the Korean evidence without using a scheme formulated for the European context. The archaeological assemblage must be analyzed with respect to the unique processes that might have determined Palaeolithic Korean technology. These early Korean assemblages are not equivalent to Mode 1 (Oldowan) and Mode 2 (Acheulean) toolkits from temporally and geographically remote regions such as western Europe, although in some early models such toolkits were assumed to represent the earliest stage of the Korean Palaeolithic. Korean assemblages are instead best evaluated with reference to other East Asian regions (Chung 1992).

The most iconic feature of the Korean Early Palaeolithic is the presence of hand axes (non-classic Acheulean bifaces). Initially, researchers compared these artifacts to Afro-European Acheulean hand axes (Kim and Chung 1978). By the end of the 1990s, Korean hand axes were implicitly connected to Western traditions, with little effort made to discover regional and temporal stylistic traits. Palaeolithic archaeological finds discovered in Korea before the 1990s were interpreted in the context of unilinear evolutionary theory. These interpretations stressed a single cultural trajectory and uniformity of patterned toolkits and often used a cultural-historical approach that emphasized migration and diffusion (Kim 1986). Varying archaeological perspectives coexisted but never matured into a coherent paradigm. As in the case of Japan, where the cultural-historical approach also dominated, for a long time archaeologists could not abandon the social transformation scheme (Ikawa-Smith 1982; Trigger 2008).

The extraordinary survival, lack of classic morphological features, and unaltered typological attributes of Korean middle-late Pleistocene assemblages do not conform to these two paradigms, however. Archaeologists today recognize that Korean hand axes are morphologically distinct from hand axes west of the Movius Line. Their main question has changed from "Why were hand axes made?" to "Why were hand axe-like tools made?" This change in perspective has opened up their willingness to detect unique lithic patterns. Greater emphasis on uniqueness than ubiquity is now placed on hand axes and associated lithic elements in Korea. This article discusses the ways in which characteristics of the Korean Early Palaeolithic do not conform to older universal schemes that tended to neglect cultural variation and subsumed all idiosyncratic variations within simplistic predetermined assumptions.

\section{THE MEANING OF "EARLY" IN KOREA}

Archaeology was not a familiar academic subject in Korea before the last half century. It is not surprising that Western-formulated terms and definitions were applied to Korean Palaeolithic variation. Due to the infancy of Korean Palaeolithic research, there has been little determination of regional-specific characteristics, although most scholars trained in archaeology were interested in historical particularism. Instead, universal generalizations were used to describe sparse, poorly dated lithic materials.

Three cultural stages, including the Early, Middle, and Upper Palaeolithic periods, were initially believed to be the most appropriate chronological terms for describing 
variation in Korean artifacts. Starting in the 1980s, archaeologists began questioning the paucity of scientific determinations made using ${ }^{14} \mathrm{C}$ dating methods (Nelson 1986). Combined with chronometric applications, the relatively low resolution of records of the Quaternary landscapes and environmental features significant to hominin adaptations impeded developing a realistic succession of cultural stages. Scholars emphasize a certain degree of material regularity in order to specify cultural phases in a universal model of development (Trigger 1986); this was the primary approach used for defining the Korean Palaeolithic (Lee 1984; Park 1992a). The sparse archaeological record then available only allowed scholars to answer cultural-historical questions about the Korean Palaeolithic in line with unilinear evolutionary paradigms. The idea that a single coherent cultural trajectory linked Korean to Western chronologies was not critically questioned or realistically assessed until the early 2000 s.

In order to describe the progressive cultural changes within a universal epoch, the occurrence of cultural markers must be observed. Clark's (1969) model of five technological modes provides a simple and effective comparative tool for assessing extremely varied temporal and spatial differences. ${ }^{1}$ Clark did not originally develop a unilinear scheme (Gamble 2001); his five modes were misunderstood as stages in unilinear cultural succession. Although Clark's (1969) model was not openly adopted by all the early researchers investigating the Korean Palaeolithic, most did presume each of the type fossils would demonstrate a series of transformations that could be placed into a simple, global scheme of increasing technological complexity over time. Modes 1 and 2, represented by chopping tools and hand axes, were regarded as archetypal forms for earlier periods, while the appearance of prismatic blades (Mode 4) and microblades (Mode 5) were considered to be exemplars of later periods. Flake tools produced by Levalloisian reduction (Mode 3) were placed in the middle of this presumed chronological sequence of lithic types.

Additional archaeological data, including finds at Chongokni, revealed that some tools were old enough and their morphologies and appearances crude and archaic enough to be considered examples of Modes 1 and 2. Researchers therefore focused on fitting these tools into the "Lower Palaeolithic" in the three-stage model. If blades or microblades were recovered, they would be considered to be representative of a higher level of cognitive, technological, and general cultural development, and would be thus assigned to the "Upper Palaeolithic." A number of simply made core tools, such as chopping tools and Acheulean-type tools, were found in stratified deposits at Chongokni and other sites, as well as numerous discoveries of prismatic tools, such as blades and microblades, dated to later Palaeolithic horizons. However, the presence of Levalloisian-type artifacts representative of a "Middle Palaeolithic" has never been verified (Kim 2012). Although Choi (1994) argued that finds from sites such as Chongokni and Kumgul showed affinities with Levalloisian artifacts, this idea was generally rejected (Seong 2002).

A two-stage model has been introduced to account for the absence of a significant cultural marker for the Middle Palaeolithic in Korea (such as is typical of the European Mousterian) and the lack of strong technologically marked cultural changes before 40,000-30,000 years ago (Lee 2001). In this model, the conventional Lower and Middle Palaeolithic are combined and reclassified as the Early Palaeolithic. Characteristics of a Middle Palaeolithic are therefore discussed in this article to clarify the definition of the Korean Early Palaeolithic.

Artifacts from the period prior to c. 40,000-30,000 years ago do not show significant cultural and technological changes. Neither artifacts dating from the middle 
Pleistocene ("Lower Palaeolithic") nor those from the early late Pleistocene until 40,000-30,000 years ago (tentatively regarded as the "Middle Palaeolithic") represent major cultural and technological breakthroughs such as are seen in artifacts from western Europe. Nevertheless, it must be noted that many scholars argue that the absence of strong cultural markers does not automatically indicate the absence of a Middle Palaeolithic in Korea. Even today, some Korean scholars continue to use the term "Middle Palaeolithic" (Choi 2010). Sites that date between 80,000 and 40,000 years ago are usually considered Middle Palaeolithic sites (Park 1992a).

Park claimed that cultural periods should be determined either by typology or time range (Park 1992b). Favoring the latter approach, he defined the Middle Palaeolithic as coinciding with the early stage of the last Alpine glaciation period (i.e., the Würm) 80,000-40,000 years ago. Other authors following Western criteria did not link cultural periods to Alpine glaciation epochs, but still determined them in relation to time span. Any culture that existed anywhere in the range from 250,000 to 40,000 years ago could be considered Middle Palaeolithic (see review by Seong 2012). Therefore, any artifacts that could be dated within that range would be classified as Middle Palaeolithic (Lee 2002). In reality, Korean Palaeolithic sites have rarely been dated to more than 100,000 years old (Lee 2013a). Thus the date range of between 80,000 and 40,000 years ago is generally accepted as representing the Middle Palaeolithic in Korea.

Although none of the techno-complex breakthroughs have been observed in Korea, the increasing number of small tools and decreasing number of large cutting tools are characteristic of assemblages dated to the Middle Palaeolithic (Yi 2002). Yi (2000) argued that assemblages prior to the Late (Upper) Palaeolithic should be divided into hand axe-yielding and the non-hand axe-yielding assemblages, with the former preceding the latter. Furthermore, he described small tools that are regarded to have transitional features between hand axe and prismatic tool assemblages (Yi 2000, 2002).

Meanwhile, Lee (2002) stated that the pebble tool tradition, introduced in the Lower Palaeolithic in Korea, was critical for understanding earlier lithic traditions. He also addressed the persistence of the pebble tool tradition during later periods (Lee 2002). Yi and Lee both adhere to western chronologies, although the details of the techno-complexes that they have examined vary. By contrast, other scholars intentionally avoid the term "Middle Palaeolithic" and instead emphasize parallel coexistence between tool assemblages (e.g., Seong 2009). More specifically, Seong (2003) interprets the differential representation of variants in Darwinian evolutionary terms (see also O'Brien and Lyman 2000). He argues that a hand axe-chopper-polyhedral dominant tradition initially prevailed prior to blade and microblade assemblages and that a small quartzite artifact dominant tradition was gradually introduced during earlier occupation periods (Seong 2006). Although he has sought evidence of transitional episodes, he strongly emphasizes the overlapping existence of different assemblages.

Attempts to evaluate small tools were made more complicated by increasing archaeological data. In many cases, small tools are strongly associated with the hand axe-chopper-polyhedral dominant tradition (Lee 2013a). Moreover, small tools have been observed for almost the entire Korean Palaeolithic (Kim 2012). Most sites do not exhibit clearly distinctive features between large cutting tools and small tools (Lee 2013b). It is becoming difficult to reconcile recent archaeological finds with the earlier expectation of finding distinct small and large tool assemblages in clear chronological succession. Archaeologists working in China similarly assumed that tool size related to chronology (Norton et al. 2009). However, equating smallness with 
technological advancement over time might make it difficult to interpret lithic variation in East Asia. It might be best not to treat large and small assemblages as distinctive cultural traditions (Dennell 2009).

In Korea, at least, cultural traits do not clearly distinguish the conventional Lower and Middle Palaeolithic periods. Indeed, tools dated to these periods exhibit overwhelming technological homogeneity. Initially, many authorities assumed material culture would have changed in distinct ways, representing a progressive succession. For example, Middle Palaeolithic tools would be more regular in form compared with earlier tools (Park 1992b). Similar to the (often misdirected) focus on small tools, changes in regularity of form are not observed before the advent of prismatic blades; instead, expediently made tools without standardized form are common (Lee 2013b). Tools in the Lower Palaeolithic techno-complex do not differ significantly from tools in the Middle Palaeolithic techno-complex. Chopping tools and hand axes are equally observed in both periods (Appendix). Sites yielding hand axes are pervasive and sites dominated by chopping tools are equally and evenly distributed through time. Therefore, the proposition of chronological distinctiveness in hand axe and nonhand axe-yielding assemblages is becoming too poorly supported to warrant a firm segregation of Palaeolithic periods based on this criterion. As there are no significant differences in size and regularity, models that assume a reduction in tool size or increase in standardization over time cannot be applied to the earlier Palaeolithic record in Korea. Other efforts to define a Middle Palaeolithic for Korea have likewise been unsuccessful.

\section{OVERVIEW OF EARLY PALAEOLITHIC RESEARCH IN NEIGHBORING REGIONS}

The widespread range and refined appearance of hand axes in the "non-classic Acheulean style" discovered in Korea initially led scholars to compare these tools to those from Western contexts. Comparing them to lithic typological traditions from regions east of the Movius Line provides a different perspective, but during the Cold War before the 1980s, academic communications between Korea (and the West) and geographically neighboring but sociopolitically remote regions such as China, Japan, and Siberia were difficult. Since these four regions have had very different modern histories, each region has established different archaeological traditions. The recent opening up of scholarly dialogue has provided a wealth of new information on Palaeolithic archaeology over the broader East Asia region.

Trigger (1984) notes that interpretations of the past have been linked with nationalist, colonialist, or imperialist agendas. Archaeological explanations tended to be historically constituted and differed greatly from country to country. Postcolonial Korea, like its neighbors, rapidly developed a distinctly nationalistic archaeological perspective intended to foster a cultural and ethnic identity. The Korean government strove to control the "authentic domain of identity" even as the public and private sectors increasingly demanded wide dissemination of archaeological research on the Korean past (Pai 2000:14). In short, the practice of Palaeolithic archaeology has mirrored a contemporary sociopolitical context and interpretations of material cultures have been shaped by these conditions. Developing archaeological interpretations in the broader context of East Asia was difficult due to the historically uncomfortable relationship between Korea and Japan and the political barriers between the former Soviet Union and China. 
Korea, China, Japan, and Siberia have very different sociopolitical orientations, but share one important interest: all oriented their research toward already established global models rather than regional models of the Palaeolithic period. The terms for chronological periods, artifact types, and lithic technologies that had developed in Europe to describe their own Palaeolithic cultures were treated as universal codes in East Asia. It is likely archaeologists adopted Western models to interpret the Palaeolithic in these four Asian regions as a matter of convenience; they probably did not weigh the suitability of these models for the East Asian context.

The Palaeolithic period is an equally new area of study in all four regions of Asia. The study of the Korean Palaeolithic was initiated in the 1960s by a culture history professor at the University of Wisconsin-Madison, Chester S. Chard, when his students became interested in Asian archaeology (Sohn 2002). Japanese archaeologists tended to focus on establishing unique cultural phases such as Jomon, Yayoi, and Kofun in later prehistoric periods (Mizoguchi 2006), but have approached the Palaeolithic by taking a broader international outlook (Hudson 2005). The most famous Chinese Palaeolithic site, Choukoutien (Zhoukoudian), excavated in a ChineseEuropean joint venture (Bar-Yosef and Wang 2012), is still interpreted using universal evolutionary models. Siberian archaeological research dates back to the nineteenth century, giving it the longest history of these four regions (Buvit and Terry 2011). Even during the Soviet period Palaeolithic discoveries from Siberia were usually compared to those from Western Europe, not East Asia (Dolitsky et al. 1985).

In the 1990s, Korean Palaeolithic researchers had more opportunities to become conversant with the archaeological data of East Asia. A symposium held in 1992 was a seminal conference for the internationalization of Korean Palaeolithic research (NRICP 1992). Interactions with scholars from neighboring regions have since increased due to political reconciliation and shared economic interests in the region; the demand for East Asian Palaeolithic studies has also increased. Since gaining more opportunities to examine Palaeolithic data from neighboring regions, it has become apparent to researchers that cultural changes (reflected particularly in lithics) did not progress during the East Asian Palaeolithic as originally envisioned. In Japanese Palaeolithic studies, the scarcity of evidence from earlier than 30,000 years ago suggests that chronological generalizations are misguided. The few Palaeolithic finds c. 40,000 years old from Sozudai, Gongeyama, Fukui Cave, and Kanedori (Matsufuji 2011) are insufficient for identifying the presence of a pre-Upper Palaeolithic period in Japan (Yi 2013:50). The concentration of Late (Upper) Palaeolithic sites compared to the entire Palaeolithic period sequence is clearly visualized in Japan. About 1400 Palaeolithic sites have been reported in Japan, almost all of which are dated to the Upper Palaeolithic (c. 33,000-13,000 B.P.) (Morisaki 2012:56). Unlike Japan, evidence for Early Palaeolithic occupation of Korea is relatively well supported. Comparing the Korean data with those of other regions thus demonstrates that cultural development was not uniform during the Palaeolithic and that the Early Palaeolithic in Korea was unique.

Although the lithic evidence dating from before 30,000 years ago is clearly present in Korea, how far back in time the record goes is a matter of debate. The debate is centered on the site of Chongokni, which is variously considered either dating to the middle Pleistocene (Bae et al. 2012; Norton et al. 2006) or late Pleistocene (Yi 2010, 2011). Similarly, the validity of the earliest Siberian sites (i.e., Filimoshki, Ust'-Tu, Zasukhino, Diring Yuriakh, etc.) has been questioned and the presence of the Lower Palaeolithic in Siberia debated (Buvit and Terry 2011; Vasil'ev et al. 2006). 
However, unlike in Korea and Japan, there are clear signs of what are commonly considered Middle Palaeolithic cultural features in Siberia. The Levallois technique of lithic production is frequently observed there, but this and other presumed Middle Palaeolithic features are not firmly dated to the middle Pleistocene. The Levallois technique does not appear until relatively late and persists even later than in western Europe (Vasil'ev et al. 2006). Although concrete evidence for the Middle Palaeolithic in Siberia is available for scholarly scrutiny (Derevianko 2010), most sites are considered to date to the late Middle Palaeolithic. For this reason, active research has been carried out on the Middle-Upper Palaeolithic transition, while intensive studies of the Lower-Middle Palaeolithic transition are lacking.

The absence of evidence for the Levallois technique in Korea makes it quite unlikely that the Korean and Siberian regions had any close cultural relationships during the Early Palaeolithic. In contrast, the connection between blade and microblade toolkits from the two regions is persuasive. Some authors consider the presence of such toolkits in Korea to indicate a Siberian origin (Bae 2010a; Bae and Bae 2012); others argue that some entities are seemingly related to local development (Lee 2002). Normally, such prismatic tools are regarded as belonging to the Late Palaeolithic. On the other hand, recent studies suggest that the Levallois technique spread to Asia earlier than 41,000 years ago (Morgan et al. 2014). Radiometric dates indicate that the Levallois technique occurred prior to the Late Palaeolithic in East Asia. It should be noted that blades are normally found alongside other blades that were made using either the Levallois technique (blades that had been made with the Levallois method) or not (blades made without the Levallois method), and that blade production does not have to be more complicated than the manufacture of Levallois flakes (Bar-Yosef and Kuhn 1999). Perhaps the serial founder effect as decribed by Lycett (2011) can be used to explain the patterns found in Korea - that is, tools of higher complexity may not easily survive, while tools of lower complexity might persist throughout vast geographic areas over long periods of time (Lee 2013a). The idea that all blades are products of the Late Palaeolithic should therefore be reconsidered. While blades are iconographic of the Late Palaeolithic, blades were also made in the "Middle Palaeolithic" using either a Levalloisian or non-Levalloisian technique.

Unlike any other region of East Asia, China has provided evidence of long-term occupation. The presence of a Lower Palaeolithic period is clear and abundant. Palaeolithic finds are evident since the early Pleistocene. Palaeolithic cultural patterns in China are divided into distinct traditions north and south of the Qinling Mountains (Bar-Yosef and Wang 2012; Dennell 2009). Some morphological differentiation has been explained in terms of spatial variability (i.e., core-and-flake industry in the north, preference for the use of river cobbles in the south). All of these toolkits are considered characteristic of Mode 1 (Oldowan-like) toolkits. The appearance of (nonclassic) Acheulean hand axes at about 800,000 years ago (Hou et al. 2000) supports the validity of the Movius Line. However, the low number of hand axes and related sites, along with idiosyncratic morpho-typological features inevitably has led scholars to doubt whether Chinese hand axes are true Acheulean hand axes (Corvinus 2004; Gao 2011; Lycett and Gowlett 2008; Norton and Bae 2009).

Comparative studies have been carried out not only because of geographical proximity but also because Korean hand axes are similar to Chinese hand axes (Kim 1993). In addition, the three premises (ratio of hand axe sites, percentage of hand axes in assemblages, and shape attributes, especially thickness) of the Movius Line sensu lato can be applied equally to both regions (see details in Norton and Bae 2009). Nevertheless, 
an important point of argument is based on biased chronology. Chinese hand axes date to the middle Pleistocene and earlier (Dennell 2009; Gao 2011), while similar Korean hand axes persist even until the latter part of the late Pleistocene. This late occurrence of Korean hand axes should be considered in future studies.

The Levallois lithic technique is even more idiosyncratic in China than in Korea. Although Levallois artifacts were found at Shuidonggou in northern China (Peng et al. 2012; Qu et al. 2013), they are interpreted as lepto-Levallois (Brantingham et al. 2004). Sites at which Levallois hand axes are found are even more rare, so it is difficult to assess the presence of the full-fledged Levallois technique in China. The traditional Western Levallois technology is regarded as critical to the appearance of Acheulean hand axes (Ambrose 2001). Since there is no sign of Levallois technology in Korea, the conventional model of an East Asian cultural inheritance should be challenged. The absence of the Levallois in Korea implies that hand axes in Korea and China do not represent common cultural traditions or historical connections. On the contrary, the different toolkits found in Korea and China may represent independent functional adaptations.

Gao and Norton (2002:408) propose seven essential points for explaining the absence of Middle Palaeolithic sites in China: usage of local raw materials; application of simple flaking methods; irregularity of flakes; simple and casual manufacture on retouched tools; low degree of lithic type variation; ambiguity in tool forms; and increase in small-sized tools. They argue that changes over time were too subtle to segregate Lower from Middle Palaeolithic periods in China. This is similar to the debate about the Korean Middle Palaeolithic already discussed. Korean and Chinese sites that have previously been classified as Middle Palaeolithic would fall into the Early Palaeolithic in the two-stage scheme.

China, especially in the north, shows evidence for all five of Clark's (1969) technological modes, although some modes are rarely found. Possibly all five modes are observed in successive sequence. The lithic assemblage is truly expedient, especially in northern China. For example, the Nihewan Basin offers rich and very old (1.7-1.6 myr) Oldowan-like (Mode 1) assemblages (Ao et al. 2013). Succeeding these tools are associated hand axe tools, found in the north as well as the south. Among four zones with concentrations of hand axes in China, three (Danjiangkou, Luonan, and Hanzhong) are located in the north (Gao 2011). The famous and controversial Levallois evidence of Shuidonggou was found in northwestern China (Brantingham et al. 2004). A proliferation of blade and microblade assemblages also occurs in northern China (Qu et al. 2013).

All five modes are not observed in other regions of East Asia. Korea's earliest assemblage is the hand axe assemblage, not the Oldowan-like assemblage. The best examples are from Imjin-Hantan River Basin (IHRB) sites (Bae 2010b; Norton et al. 2006). As noted above, the date of first occupation of Japan is controversial, but one of the earliest Japanese sites, Kanedori, includes crude hand axe-like tools (Matsufuji 2011). Therefore, the first assemblage in Japan does not conform to a Mode 1 episode. Siberian assemblages have not yielded Acheulean hand axes, while rich signs of Levallois and prismatic blade technologies are present there. Assemblages from southern China are characterized by very consistent, expedient lithic technologies that persist over time.

Although the similarities and dissimilarities of lithics amongst the different regions of Asia are highlighted here, interpreting such variations is not straightforward. East Asia is so vast that it is almost impossible to describe any widespread "Asian" 
Palaeolithic features. The Palaeolithic of the eastern Old World is not homogeneous, as previously thought, and it is difficult to formulate general criteria for describing the Palaeolithic in East Asia. The wide range of lithic variation observed across East Asia must therefore be addressed. The most important question is: why is there so much variation?

In a broad sense, marine isotope stage (MIS) 3 is the earliest period for which substantial quantitative and qualitative Palaeolithic evidence is available. However, evidence prior to MIS 3, which falls in the Early Palaeolithic, has shown more biased, sporadic, and uneven Palaeolithic features. These artifacts can be viewed as forms of information that were shared and transmitted, and cultural diversification occurred throughout the acquisition and inheritance of information. There may have been extreme variations in the degree of shared and transmitted information between foraging groups. Previous studies mainly focused on broad cultural properties, but variation across the extended region has started to be seen as reflecting "distinct socially learned patterns of behavior" (Lycett and Gowlett 2008:297). This point of view highlights the dynamic nature of the sharing and transmitting of information through demographic factors. Several related observations from the demographic point of view are summarized below.

First, except in northern China, East Asian regions do not exhibit all five of Clark's modes, which is perhaps not surprising since they were formulated from studying Western lithic successions (Shea 2011). Each East Asian region has distinct features, making it easier to identify dissimilarities than similarities. There is no single or universal cultural trajectory by which to explain the whole of East Asian assemblages. Consequently, it is difficult to identify general cultural criteria to describe cultural epochs in East Asia. One reason for the lack of regular cultural succession may have been population size (Shennan 2001). However, the most important factor is not the actual number of people, but effective population size. Static and sometimes reclusive lithic technology can be explained by the effects of demography on cultural transmission (Lycett and Norton 2010).

Second, across East Asian regions, very limited occurrences of true Lower Palaeolithic assemblages are observed dated to the middle Pleistocene or earlier. Lower Palaeolithic sites from many regions are substantially younger than this (i.e., hand axe sites in Korea and China) or are completely absent in other regions; debates about the dates of these assemblages persist (i.e., the Lower Palaeolithic in Japan) (Gao 2011; Matsufuji 2011; Yoo 2009). The hand axes found in East Asia were treated as cultural markers, although they occur only rarely. The position that these hand axes are not Acheulean tools is becoming stronger (Corvinus 2004; Lycett and Gowlett 2008; Norton and Bae 2009). Hand axes in East Asia failed to proliferate or to become more elaborate through time (Lycett and Norton 2010). The low numbers of hand axes in East Asia (Norton and Bae 2009) might be explained by lack of information sharing between groups. However, they could also be explained as occurring through convergence without making any historical connections to cultural transmission (Clark 2011; Wang et al. 2012).

Third, the traditional characteristics of the Middle Palaeolithic are rare in East Asia. The Levallois technique was geographically confined to Siberia and the limited evidence from northern China cannot be identified firmly as Middle Palaeolithic. The Levallois technique is nearly absent from most of East Asia. Although there is rich Siberian evidence, it does not conform to conventional Western interpretations. In the conventional model, typical Levallois prepared core techniques initially date to 
the latter part of the Acheulean period (Mode 2) (Ambrose 2001), but Siberia lacks Mode 2. In addition, Levallois-type manufacture occurs relatively late in East Asia. The Levallois site of Shuidonggou is unique in the Chinese Palaeolithic context. It has been referred to as lepto-Levallois (Brantingham et al. 2004:240). From a phylogenetic perspective, artifact similarities can be viewed as either homologous (having a common technological ancestry and historical connections [Clark 2011]) or homoplastic (convergent evolution, independent developments [Lycett 2009]). The presence of Levallois technique without direct ancestral links to Acheulean hand axes in Siberia and the lepto-Levallois technique with direct ancestral links to (non-classic) Acheulean hand axes in northern China may complicate technological evolution scenarios. Nevertheless, the dispersal and densities of foragers in varying geographic conditions may provide keys to understanding the consequences of either homologous or homoplastic evolution.

Fifth, simply made core and flake tools that can be regarded as an Oldowan or Mode 1 assemblage occurred earlier in time in East Asia than in other regions and persisted to the Upper or Late Palaeolithic. Blades and microblades occurred in only part of East Asia and usually coexist with blade and microblade assemblages where they are found. The long, monotonous persistence of Mode 1 tools in specific regions was noted by Foley and Lahr (2003:118), who suggested that evolution did not occur in a uniform manner. In Korea, accumulating data also strongly reinforce the persistence of Mode 1 (Lee 2013a). Uneven demographic conditions throughout the vast and varied geographical conditions in Asia, including Korea, result in techno-complex variation. Under the serial founder effect, population groups whose technologies are not very efficient make less complex artifacts such as Mode 1 toolkits, while highly effective population size free from the serial founder effect might accomplish complex cultural transmissions (Lycett and Bae 2010; Lycett and Norton 2010).

Many authors have argued that demographic factors have an important influence on cultural maintenance and transmission, but it is very difficult to formulate a model predicting cultural transmission from population size (Powell et al. 2010). East Asia has extremely different and inconsistent Palaeolithic records for each region. The wide spectrum of variation is probably explained by numerous mechanisms: strong cultural transmissions (clear ancestral-descendant connection); weak cultural transmissions (the founder effect); and non-cultural connections (convergence). The most important point is that no single mechanism appears to have predominated. If the transmission of learned traits is viewed as part of cultural phenomena, innovative ideas cannot always spread successfully due to noise in the transmission (O'Brien and Shennan 2010:7).

\section{FINDING HAND AXES IN THE ARCHAEOLOGICAL RECORD}

Hand axes in Korea are treated as part of the Korean Palaeolithic domain; they are encompassed in all major Palaeolithic vertical and horizontal debates. Looking vertically at the history of Palaeolithic research, past interpretations have been reconsidered. Chongokni, a site excavated in the 1970s, has been continuously revisited; previous typological and chronological interpretations are now being deeply criticized. According to a 2007 report by the Institute of Cultural Properties (ICPH) at Hanyang University, 13 different excavations have been conducted at Chongokni and additional research is ongoing. No other sites in Korean Palaeolithic research have been addressed with such intensity. 


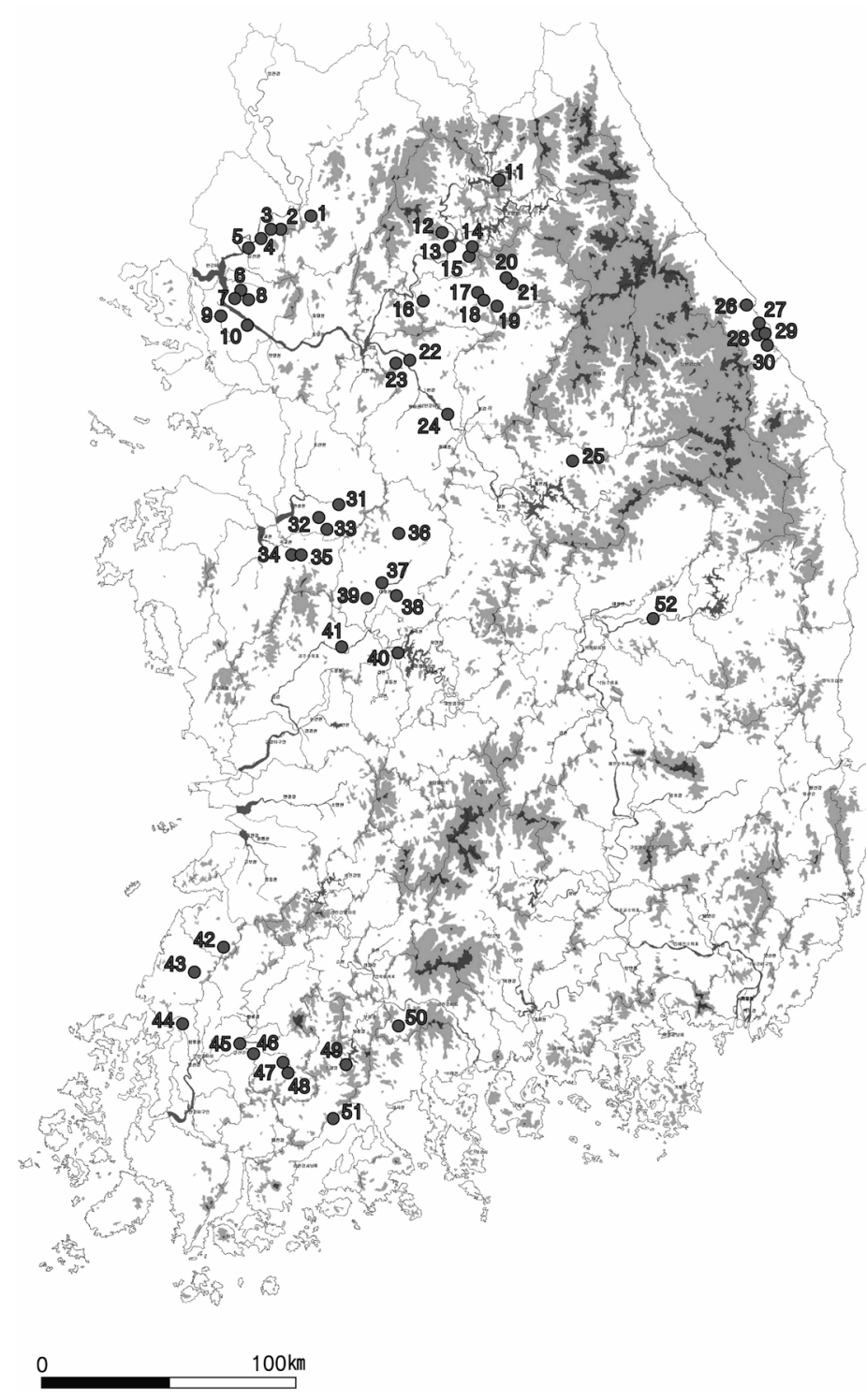

1. Chongokni

2. Chuwoli/Kawoli

3. Jangnamgyo

4. Kumpari

5. Jangsanni

6. Unjeong

7. Deogidong

8. Tanhyeondong

9. Janggidong

10. Singokri

11. Sangmuryongri

12. Seosangri

13. Galdun

14. Mancheonri

15. Geoduri

16. Mogokri

17. Baeki

18. Jageunsolbat

19. Yeonbongri

20. Guseongpori

21. Nae/Oesampori

22. Dogokri

23. Byeongsanri

24. Yeonyangri

25. Segeori

26. Shimgokni

27. Manghaedong

28. Balhandong

29. Wolso

30. Pyeongneungdong

31. Gaejeongri

32. Usinri

33. Suheolri

34. Sirokdong

35. Gwongokdong

36. Songduri

37. Sorori

38. Bongmyeongdong

39. Mansuri

40. Nosanri

41. Seokjangri

42. Jeungsan

43. Wondang

44. Danghasan

45. Dangga

46. Domindong

47. Dosan

48. Sachang

49. Kogchon

50. Jungnaeri

51. Sukpyeong

52. Maaeri

Fig. 1. Locations of major Early Palaeolithic Korean sites. Source base map MOLIT 2010.

Major concerns have shifted, however, from attempts to broadly understand the Korean Palaeolithic in the context of global archaeological perspectives to identifying distinctive regional morpho-typologies that might provide more specific understandings of local technology and human behavior. The changing avenues of research are considered promising because of increased opportunities to make horizontal comparisons with archaeological finds from neighboring regions. The increased availability of archaeological records in Korea and interest in East Asian hand axes initially led to a reevaluation of the classic Movius model. There is persuasive evidence for the persistence of non-classic Acheulean hand axes and a stagnant pattern of variation east 


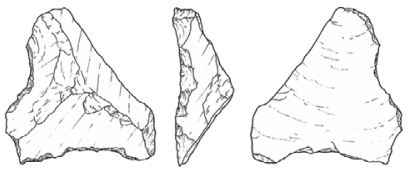

(1)
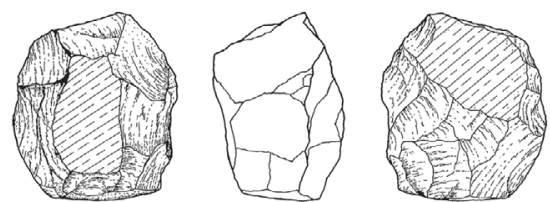

(4)
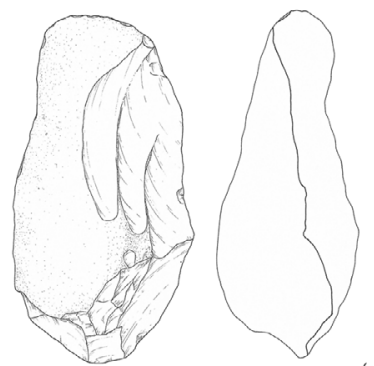

(6)
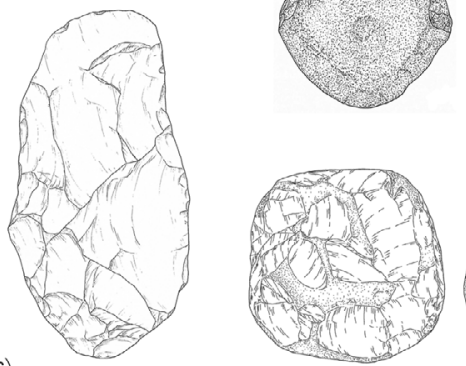

(9)
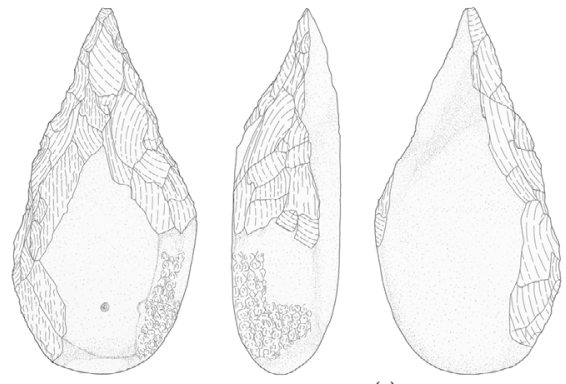

(11)
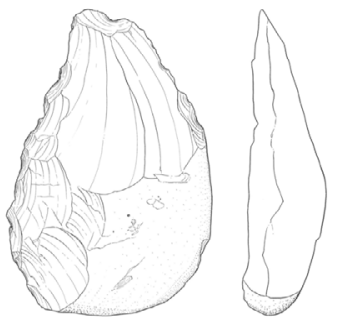

(10)
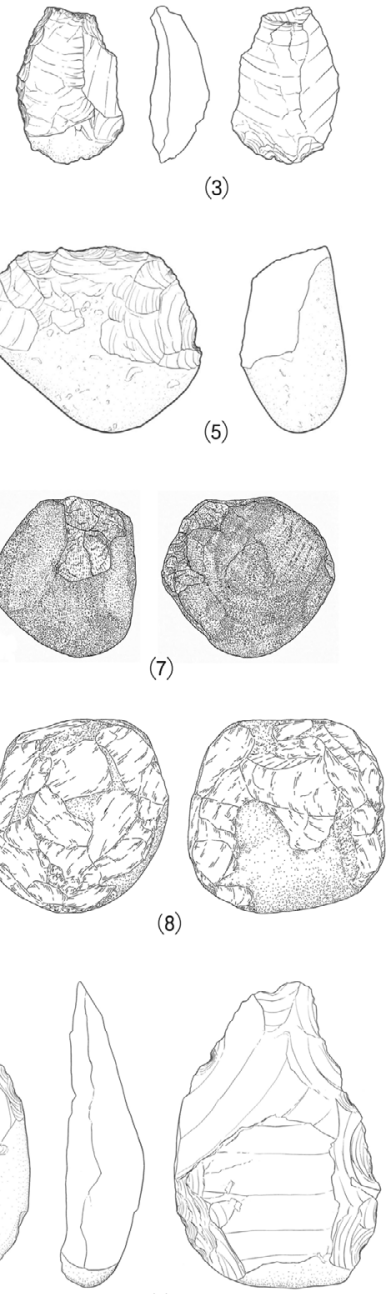

(3)
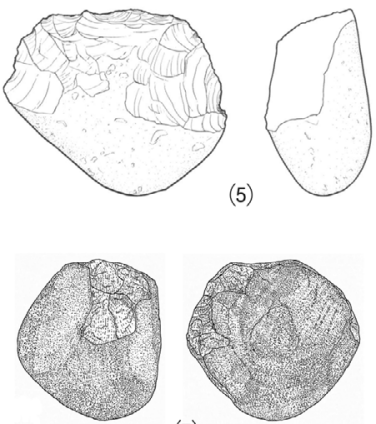

(7)

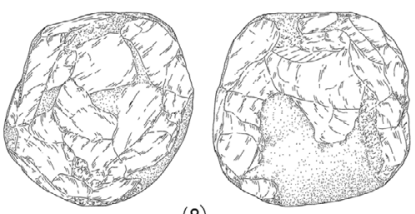

(8)
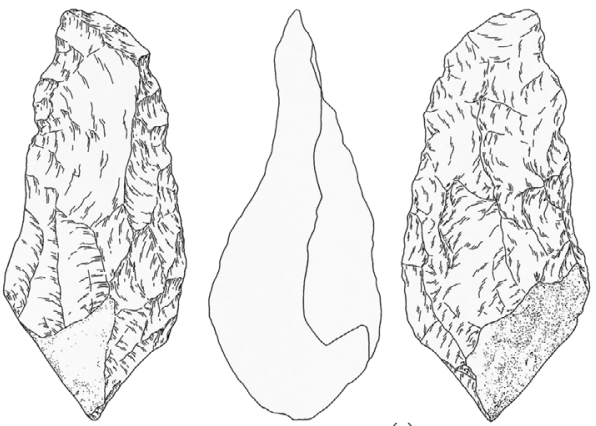

(12)

$10 \mathrm{~cm}$

Fig. 2. Early Palaeolithic artifacts from selected Korean sites: Unjeong (1) notch, (2) awl, (6) cleaver (IKP 2012c, 2012d); Galdun (3) scraper, (5) chopper, (10) hand axe (Choi and Kim 2008); Chongokni (4) heavy-duty scraper (ICPH 2001); Baeki (7) polyhedron (GRICP 2009a); Mansuri (8) polyhedron, (12) hand axe (Y.-J. Lee et al. 2009); Jangnamgyo (9) hand axe (Bae et al. 2011); Pyeongneungdong (11) hand axe (Ji et al. 2007). 
of the Movius Line. Efforts to identify similarities and differences in hand axe records between regions east and west of the Movius Line have solidified the concept of the Movius Line sensu stricto and sensu lato (Norton et al. 2006; Norton and Bae 2009; Petraglia and Shipton 2009).

In addition to comparisons between the East and West, growing awareness of the importance of intra-correlative works within the East has offered the opportunity to characterize East Asian lithic variation in more elaborate ways. Chinese and Korean hand axes have been compared metrically. Archaeologists have then debated whether or not their variations can be explained by different processes such as cultural dispersion or convergence (Lycett and Bae 2010; Petraglia and Shipton 2008).

During the early period of hand axe research in Korea, adequate references for making comparisons were not available. Since no persuasive typological and chronological frameworks had been established in Korea and scholars lacked expertise in Palaeolithic archaeology, following Western models was the only way to interpret Korean archaeological findings. The major tasks of Korean archaeologists during the 1960s and 1970s were to describe variations in form and type and identify origin and dispersal patterns. Following the European cultural-historical approach, their fundamental quest was to extend Korean history back into the remote past, so they tended to assume archaeological variation had occurred by means of diffusion and migration (Trigger 2008:248).

The biggest problem with studying Korean hand axes in the 1960s and 1970s was that early data were not available. There was as yet no hard evidence for the presence of the Palaeolithic period in Korea. A consensus that Korean prehistory could be older than the Neolithic period had not yet matured. The presence of hand axes had already been noted in the 1960s in southern (Sohn 1967, 1969) and northern Korea (IA 1969). Implements found at Seokjangri and Gumumoru were described as either "hand axes" or "hand axe-like." During this period of research, some scholars may have considered Korean hand axes to be idiosyncratic rather than evidence of the Palaeolithic in Korea.

When Sohn first found hand axes from Seokjangri in the 1960s, he may have recognized the potentially important nature of the discovery, as can be seen in his communications with many other scholars, including Movius (Sohn 1967:22). He also described the rarity of hand axes east of the Movius Line (Sohn 1972:10). He promoted a similar concept to the Movius Line sensu lato (for use of the term, see Norton et al. 2006) and pointed out that the hand axes from Seokjangri were crudely made and resembled proto-hand axes (Sohn 1968: 13) or Abbevillean tools (Sohn 1967:22). He explained their sporadic occurrence as due to raw material conditions (Sohn et al. 1982). He argued that the extremely low percentage of hand axes at Korean sites meant that hand axes could not be regarded as markers of local cultural traditions. Because the dominant tool types were simple core and flake tools, not hand axes, he described these sites as representing "pebble tool culture" (Sohn 1968), a definition relevant to the "chopper-chopping tool" tradition proposed by Movius (1948). His contemporaries, assuming a diffusion and migration model, also referred to a regional "Asiatic chopping tool tradition" (Hwang 1970:22).

Acheulean-like (identified at the time as "Mid-Acheulean") hand axes from Chongokni were excavated in the late 1970s (Bae 1988; Kim and Chung 1978). These finds garnered attention from both the academic and public sectors. The greater attention afforded these finds was because of the numerous forms of hand axes discovered in 
Chongokni, as well as the efforts of Western scholars who tried to compare them with typical materials from the West. After visiting the site in 1979, Desmond Clark suggested that these were not typical Acheulean hand axes, but still tried to compare them to Western types (RICP 1983).

Controversy arose around the discovery of more hand axes at Chongokni in the 1970s and 1980s. Some scholars believed that these were identical to Acheulean hand axes (Chung 1983), while others noted only that they bore some similarities (Hwang 1983). The Korean hand axes were compared to the African Sangoan (Hwang 1983; Kim and Bae 1983:86) and were considered part of the African-European Acheulean lithic tradition (Kim 1986:13). Scholars following typologies designed for lithic patterns from other parts of the world used terms such as "Acheulean" to describe these Korean artifacts.

At the same time, some researchers attempted to interpret these tools as part of an Asiatic cultural tradition. Since these scholars followed the cultural-historical approach, in which changes were explained by diffusion and migration, they focused on attempting to locate the origin of these tools within East Asia. Bae (1983) attempted to describe Chinese cases and compare them with Korean implements, while Kim (1986) addressed possible hand axe routes. It was suggested that the presence of homogeneous cultural identities over space within an East Asian interactive sphere was a more useful focus of research, and therefore attempts were made to link the Korean hand axes to the Chinese Palaeolithic cultural tradition (Kim 1993:8). The term "Chongoknian," coined to describe regional and temporal cultural identity (Bae 1992), was an attempt to evaluate Korean Acheulean-like tools within a confined regionally specific context. This perspective allowed for the generation of "idiosyncratic diffusionary episodes that had shaped the development of each culture" (Trigger 2008 : 219). In the late 1980s, Yi (1989) raised questions about the validity of cultural tradition theory. Since the cultural-historical approach dominated Palaeolithic archaeology, Yi's questions generally did not receive much attention.

Archaeologists initially suggested that Chongokni was approximately 300,000 years old (Kim and Chung 1978); this date was supported in subsequent studies (Bae 1988; Bae et al. 2012; Danhara et al. 2002; Norton et al. 2006). The present author has proposed that the hand axes were younger than Chongokni, which contradicted the classic notion that all hand axes dated c. 300,000 years old are similar (see discussion in Lee 2013a). Yi's (1996) explicit arguments against the chronological validity of this date created a sensation and sparked an ongoing debate. Criticism of the c. 300,000-year-old date persisted into the 1980s and 1990s, as Korean archaeologists attempted to explain the presence of multiple cultural horizons, with some of the artifacts belonging to later cultural episodes, perhaps to the Upper Palaeolithic (Hwang 1983). Later analyses by specialists using chronometric dating methods indicate that these hand axes date to the late Pleistocene and therefore support the "young hand axes" proposition (Lee 2013a; Yi 2011; Yoo 2007).

Many studies of the Korean Palaeolithic have been devoted to determining the ages of Korean hand axes. Although it is beyond the scope of this article to deal with this debate in any more detail, the influence age determinations have on interpreting how hand axe-bearing sites are related should be addressed. In the context of a culturalhistorical framework that emphasizes external influences and diffusions, the assumption that the hand axes are old provides a convenient set of reference points for asserting historical connections between hand axes from Korea and those from other 
regions. Although few sites yield securely dated hand axes in China (Gao 2011), hand axes are generally believed to occur in China as early as the middle Pleistocene (Huang 1989). Even before the discovery of the Bose and Luonan basin, which offered more refined chronological data (Hou et al. 2000; Wang 2005), the Lantian and Dingcun sites were well known to Korean scholars as far back as the 1960s (Kim 1964). The presence of hand axes at these Chinese sites was frequently referenced after hand axes were found in Korea (Bae 1983). If the notion of young hand axes is accepted, the temporal gap increases, directly undermining the "historical connection" argument.

\section{A DIFFERENT APPROACH TO THE EARLY PALAEOLITHIC}

Given the archaeological emphasis on determining clear technological markers for chronological phases, the presence of hand axes in Korea that are significantly younger in date than those conventionally known to have occurred in other regions is an awkward matter (Lee 2013a). As part of the increase in archaeological finds in Korea after the turn of the twenty-first century, many sites yielding hand axes have been reported. Interestingly enough, almost all of these findings are from late Pleistocene deposits. Sites old enough to be middle Pleistocene have been reported, but dates are not secure and there are few such sites. For example, Jangnamgyo and Jangsanni, located in the IHRB, may be as old as Chongokni (Bae 2010b; Bae et al. 2011; SNUM 2004; Yi 2011). However, recently excavated sites yielding hand axes have mostly been dated to MIS 4 and 3. Such sites are located all over Korea (Fig. 1). The sites of Wolso, Nobong, Samri, Geoduri, Galdun, Mansuri, and Jeungsan are located outside of the IHRB; none confidently date to the middle Pleistocene (see Appendix). Some, such as Ssangjungri and Jeungsan, date close to the transitional period between MIS 3 and 2. That Korean hand axes were not temporally or regionally confined contradicts previous assumptions.

The time range during which hand axes are found in Korea is very different from the traditional Acheulean hand axe chronology. The oldest Acheulean hand axes date to 1.6 myr (Gibbon et al. 2009), while the oldest hand axes in Asia, found at Attirampakkam in India and Bose in China, are as old as 1.5 myr (Pappu et al. 2011) and 0.8 myr (Hou et al. 2000), respectively. Acheulean hand axes are believed to persist until 100,000 years ago (Lycett and Gowlett 2008); they continue over a very long period of time (1.7 myr-100 kyr), but are hardly ever observed after 100,000 years ago. The suggested radiometric dates for newly discovered Korean hand axes are thus unusual for most Acheulean contexts.

Morphological similarities to hand axes found west of the Movius Line are lacking, not only in terms of visual impressions but also in metric terms. Norton and Bae (2009) noted significant discrepancies in thickness, although Petraglia and Shipton (2008) disagree. A recent study compared the ratios of measurements of hand axes from two regions (IHRB in Korea and the Thames River valley in England) (Lee 2006). Eastern and Western hand axes were similar in terms of "broadness" (calculated as breadth/length following Roe 1968), but not "flatness" (calculated as thickness/ breadth). Discrepancies in the chronologies and morphologies of different hand axe groups are thus becoming increasingly evident.

Korean hand axes do not show clear morphological changes from the middle to late Pleistocene. It is also still a matter of debate whether the oldest hand axes in Korea can be dated to the middle Pleistocene. But if they can, the question of whether 
technological complexity should have increased over time needs to be addressed. At least, it should be determined whether there are significant morphological changes over a given period of time. The bilateral symmetry test is related to determining the degree of refinement. The premise is that increasing symmetry with decreasing site age indicates increases in cultural and technological complexity. However, the relationship between these parameters remains uncertain. Analyses also indicate that the degree of hand axe symmetry is not related to climate or raw material conditions (Lee 2011).

Technological variability in Korea, as exhibited by the presence or absence of specific cultural markers, is summarized in an Appendix at the end of this article. " $\mathrm{C}$ " indicates the presence of chopping tools and equivalent toolkits, that is, the Oldowan and Asian pebble tool and chopping tool traditions (Foley and Lahr 2003 : 114) and the Clactonian in Britain (Lycett and von Cramon-Taubadel 2008). From this perspective, an assemblage yielding simple chopping tools and polyhedrons can generally be regarded as an Oldowan or Clactonian chopping tool assemblage. " $\mathrm{H}$ " indicates sites containing hand axes. This hand axe assemblage is classified as Developed Oldowan or Acheulean. C- and H-type assemblages are often difficult to distinguish due to their continuous rather than discrete variation (Foley and Lahr 2003:114) and arbitrary distinctions between the two sets of toolkits. Lithic tools from the Korean Early Palaeolithic are comparable to Oldowan (or Clactonian) or Acheulean (or Developed Oldowan) tools. Both entities exhibit chronological overlap and strong persistence over a long period of time in the Korean Palaeolithic context. Following the famous debate concerning Clactonian and Acheulean forms (Ohel et al. 1979; White 2000), it needs to be addressed whether these two entities are independent techno-complexes or not (see Appendix).

The overall impression of the Korean hand axe assemblage is that it is static over time. The Korean chopping tool assemblage likewise remains stable over time. The question remains whether these two entities are mutually exclusive. If the hand axe assemblage does not constitute an independent cultural complex, it can be treated as an integral part of another chopping tool assemblage. These simple tools are usually seen as static over time, with no major morphological or typological changes, while traditional Acheulean hand axes usually exhibit distinctive patterns at different cultural stages (Schick and Clark 2003). Although the classic cultural distinctions (i.e., proto-Acheulean, Mid-Acheulean) based on the appearance of progressive refinement are no longer considered valid, improved knapping technique over time is generally apparent in the Acheulean (Clark 2011). In short, innovation usually occurred in Acheulean tools, not in Oldowan tools. However, unlike conventional depictions of Acheulean and Oldowan distinctions, in Korea both hand axe and chopping tool assemblages show strong persistence over time without alterations in the techno-complex.

The stagnant, persistent nature of these tools has been supported by an improved understanding of earlier lithic records. Hand axes are described as examples of "expedient and opportunistic tool-making" (Yi 2011:13). In addition, coeval Oldowan-like tools are also described as "expedient and casual in nature" (Norton et al. 2006:530). Such informal tools prevailed during the entire Early Palaeolithic and even the Late Palaeolithic in Korea (Lee 2013b). There are no clear signs of technological or typological progression. Instead of being treated as distinct, both types of assemblages can be regarded as comprising a single entity referred to as "simple core and flake tool assemblages" or SCFA (Lee 2013a). 
Since the two assemblages have the same characteristic features and are expediently static, they are allied with the Oldowan, not the Acheulean. Such homogeneous, static characteristics are apparent from the perspectives of applied technology and raw material procurement patterns. Simple, direct percussion techniques prevailed; there are no clear signs of soft hammering techniques. Almost all hand axes were finished with hard hammering. Chopping tools and polyhedrons were complete during the primary knapping episode. Deliberate, regular secondary retouch for trimming the working edges or shaping for standardization of form is rarely seen in the core and flake tools. Extensive hand axe retouching is very rarely observed (Bae et al. 2012:16).

Hand axes in Korea appear to have been supplementary tools within a simple toolkit. Although they occur at many sites, the numbers of hand axes per site are low. For instance, Chongokni, the site with the highest resolution, yielded only a few dozen hand axes from stratified deposits after more than 30 years of excavations (Table 1). Korean sites yield even fewer cleavers, tools considered another hallmark of the Acheulean (Lycett and Gowlett 2008:295; Lycett and von Cramon-Taubadel 2008:553). The scarcity of cleavers in the IHRB (including Chongokni) has already been noted (Yoo 2007: 181).

If Korean hand axes were merely supplementary tools, the importance of simple tools (i.e., chopping-related) increases. Simple tools were not affected by chronological and environmental changes. They are not confined to a specific period of time in Korea, but persisted to the end of the Early Palaeolithic (Appendix). They are also found in Late Palaeolithic deposits (Lee 2013b). Just as Korean hand axes are not regarded as typically Acheulean, simple tools from Korea are also very different from typical Oldowan tools. More research needs to be conducted to determine why conventional Western schemes are not appropriate in Korea. The most challenging possibility is that cultural patterning in Korea is neither spatially nor temporally coherent and did not occur according to conventional processes of cultural transmission.

\section{CONCLUSION}

Conventional models of artifact evolution from simple to complex (Shennan 2009:2) are not particularly useful in understanding Korean Early Palaeolithic assemblages. Simply made tools persist throughout the Palaeolithic in Korea. Artifacts considered important cultural markers, such as hand axes, persist for extremely long periods of time with little morphological or typological alteration. The persistence of expedient lithic technology is also a major characteristic of the Korean Early Palaeolithic. These features make it difficult to characterize the Early Palaeolithic on a broad scale. Future analyses of regionally distinct lithic patterns might provide the key to better understanding the Early Palaeolithic in Korea.

Unlike the Western Old World, the Eastern Old World lacks major technical shifts and exhibits "continuous production and utilization of Mode 1 implements" (Norton et al. 2006:528). Even within East Asia, changing lithic reduction strategies occur inconsistently. The presence or absence of imposed forms, degree of standardization of shape, and the amount of time each specific type of toolkit persists in the record all vary between regions.

Comparing assemblages across East Asian regions presents difficulties because of inconsistent initial introductions of lithic assemblages (including hand axe assemblages). Korean Early Palaeolithic sites do not generally show strong cultural connections with 
Table i. Chongokni Hand Axes, Picks, and Cleavers in Stratigraphic Context

\begin{tabular}{|c|c|c|c|c|c|c|}
\hline $\begin{array}{l}\text { FIELD SEASON/ } \\
\text { YEAR/CONTEXT }\end{array}$ & HORIZONS & HAND AXE* & PICK & CLEAVER & TOTAL & REFERENCE \\
\hline $\begin{array}{l}1979 \text { (Seoul } \\
\text { University) }\end{array}$ & $\begin{array}{l}\text { Layer } 3 \text {, reddish } \\
\text { brown clay }\end{array}$ & 3 & 3 & 0 & 6 & RICP 1983 \\
\hline $\begin{array}{l}1980 \text { (Seoul } \\
\text { University) }\end{array}$ & $\begin{array}{l}\text { Layer } 4 \text {, sandy } \\
\text { brown clay }\end{array}$ & 1 & 0 & 0 & 1 & RICP 1983 \\
\hline $\begin{array}{l}1981 \text { (Seoul } \\
\text { University) }\end{array}$ & Layer 3 , reddish clay & 1 & 0 & 0 & 1 & RICP 1983 \\
\hline $\begin{array}{l}1979 \text { (Kyunghee } \\
\text { University) }\end{array}$ & Layer 4 , clay & 3 & 1 & 0 & 4 & RICP 1983 \\
\hline $\begin{array}{l}1980 \text { (Kyunghee } \\
\text { University) }\end{array}$ & Layer 4 , clay & 1 & 0 & 0 & 1 & RICP 1983 \\
\hline 1986 & $\begin{array}{l}\text { Layer } 3 \text {, reddish } \\
\text { brown clay }\end{array}$ & 2 & 0 & 0 & 2 & SNUM 1989 \\
\hline 1992 & reddish brown clay & 1 & 0 & 0 & 1 & Bae \& Koh 1993 \\
\hline 2000-2001 Loc. 1 & $\begin{array}{l}\text { Layer } 3 \text {, reddish } \\
\text { brown clay }\end{array}$ & 1 & 0 & 0 & 1 & ICPH 2001 \\
\hline 2000-2001 Loc. 2 & $\begin{array}{l}\text { Layer } 3 \text {, reddish } \\
\text { brown clay }\end{array}$ & 2 & 0 & 0 & 2 & ICPH 2001 \\
\hline 2000-2001 Loc. 3 & $\begin{array}{l}\text { Layer } 2 \text {, light brown } \\
\text { clay }\end{array}$ & 0 & 1 & 0 & 1 & ICPH 2001 \\
\hline 2000-2001 Loc. 4 & Layer 4 , brown clay & 1 & 0 & 0 & 1 & ICPH 2001 \\
\hline Road 2-5 & $\begin{array}{l}\text { Layer } 7 \text {, light reddish } \\
\text { brown clay }\end{array}$ & 0 & 1 & 0 & 1 & KRIMH $2010 a$ \\
\hline Road 2-5 & $\begin{array}{l}\text { Layer } 4 \text {, reddish } \\
\text { brown clay }\end{array}$ & 1 & 0 & 1 & 2 & KRIMH $2010 a$ \\
\hline Road 1-2, Loc. 1 & Layer 3 , brown clay & 1 & 0 & 0 & 1 & KRIMH 2011 \\
\hline Road 1-2, Loc. 1 & $\begin{array}{l}\text { Layer } 4 \text {, dark brown } \\
\quad \text { clay }\end{array}$ & 1 & 0 & 0 & 1 & KRIMH 2011 \\
\hline Road 1-2, Loc. 1 & Layer 6 , brown clay & 1 & 0 & 0 & 1 & KRIMH 2011 \\
\hline $\begin{array}{l}\text { Road 2-5 (Seoul } \\
\text { University) }\end{array}$ & $\begin{array}{l}\text { Layer } 3 \text {, reddish } \\
\text { brown clay }\end{array}$ & 7 & 3 & 0 & 10 & Yi et al. 2011 \\
\hline NH constriction & Layer 3 , reddish clay & 1 & 0 & 0 & 1 & Yi et al. 2006 \\
\hline
\end{tabular}

* Includes excavated hand axes only; those collected at surface omitted.

other regional traditions within East Asia, but some similarities of pattern and process have been proposed for assemblages from China. Unlike in other East Asian regions, hand axes in Korea and China exhibit coherent cultural patterning. However, the dates of the hand axes in the two regions exhibit larger gaps than was previously believed. Due to the increasing number of late hand axes discovered in Korea, theories of cultural relationships between Korea and China should be reconsidered.

Given the vast size of East Asia, effective population models are difficult to sustain due to the serial founder effect. If social transmission of information was not intense, it would explain the diversity of lithic production output. Demographic and geographic data suggesting unique cultural developments occurring in isolation, as well as through interactions and shared technology, should be more carefully considered. There will be growing opportunities for researchers to examine social and demographic factors in the future, enabling them to better interpret the varied lithic patterns in the region and translate these artifact patterns into understanding social behaviors among Early Palaeolithic populations. 


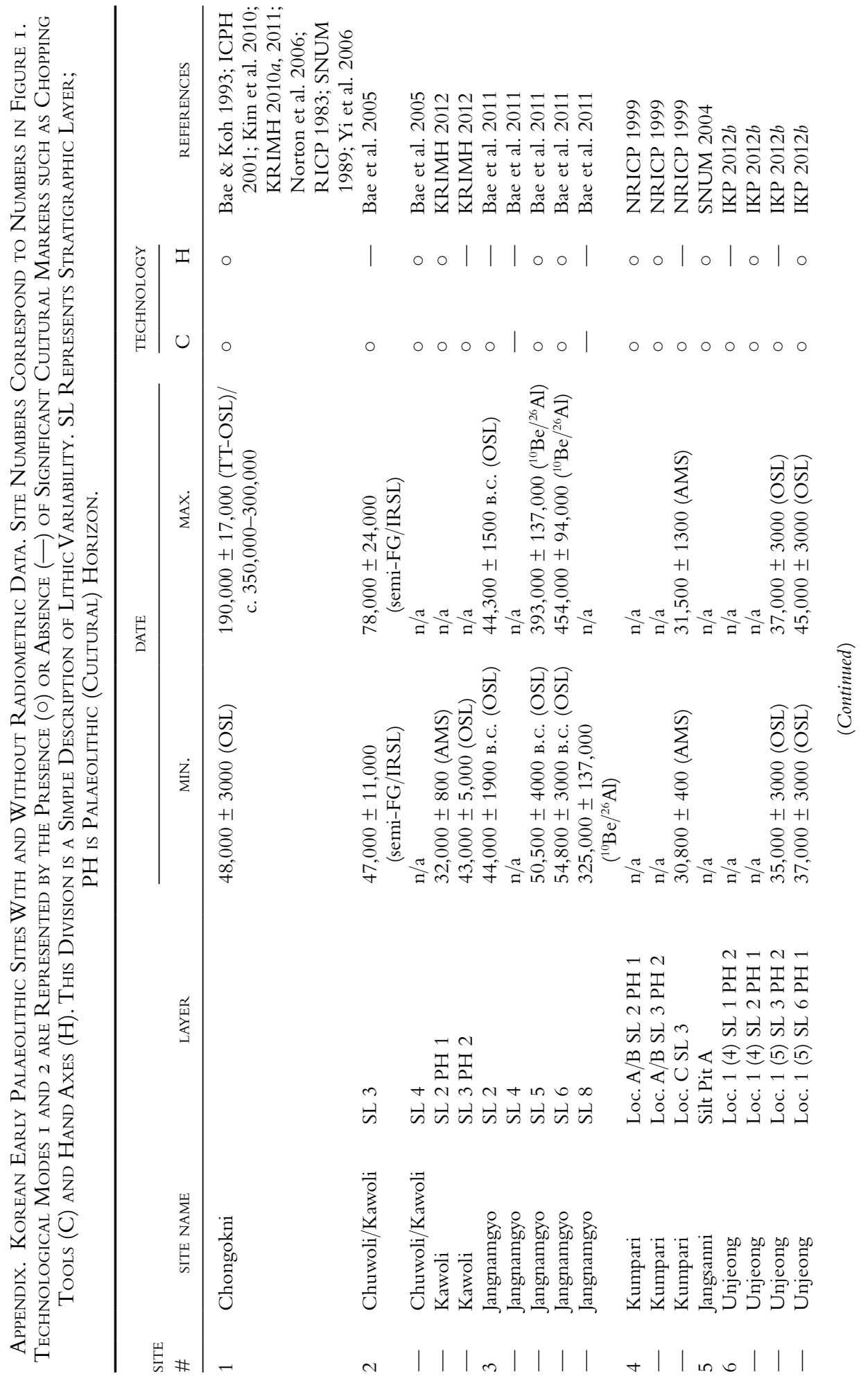




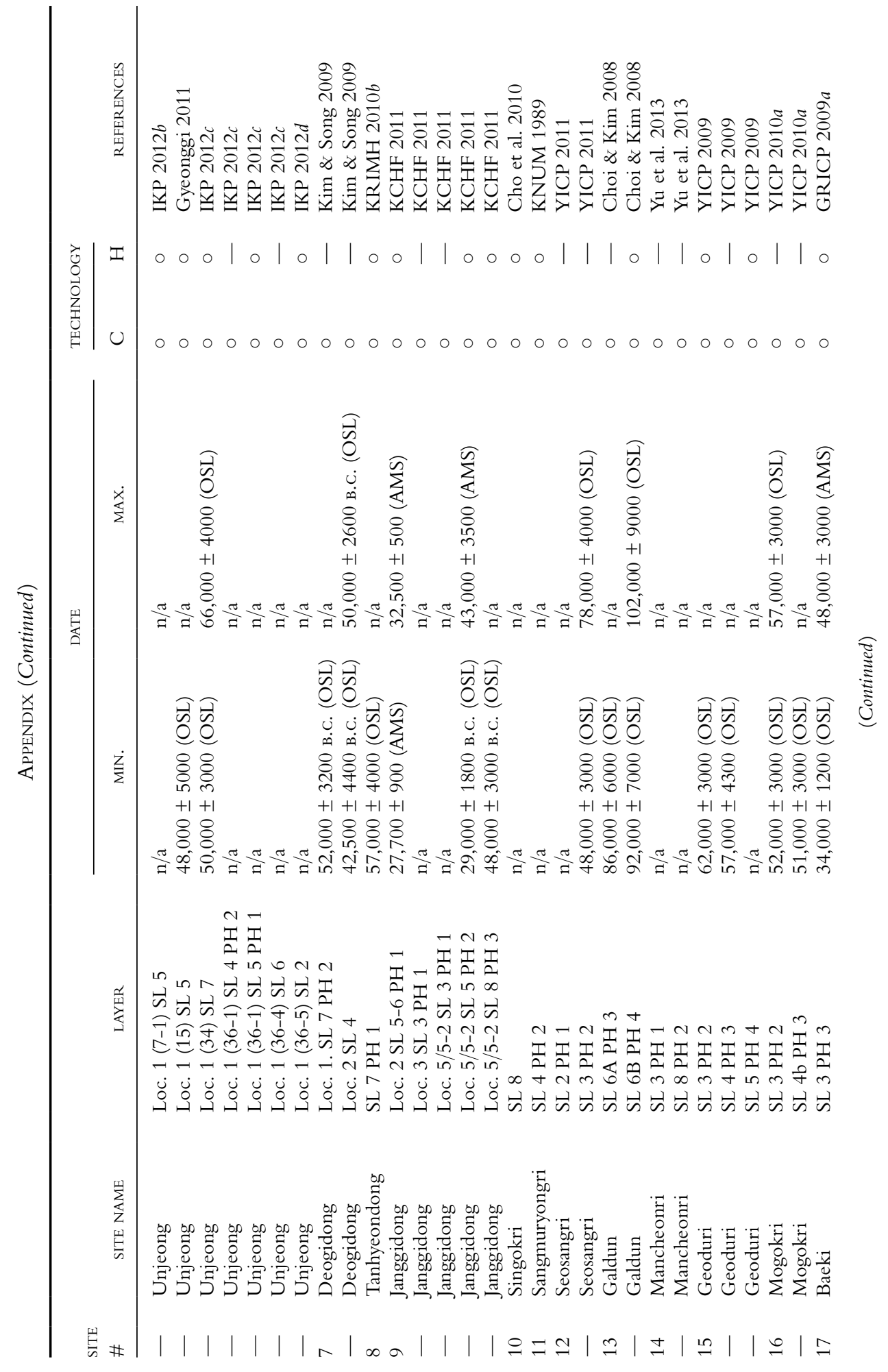




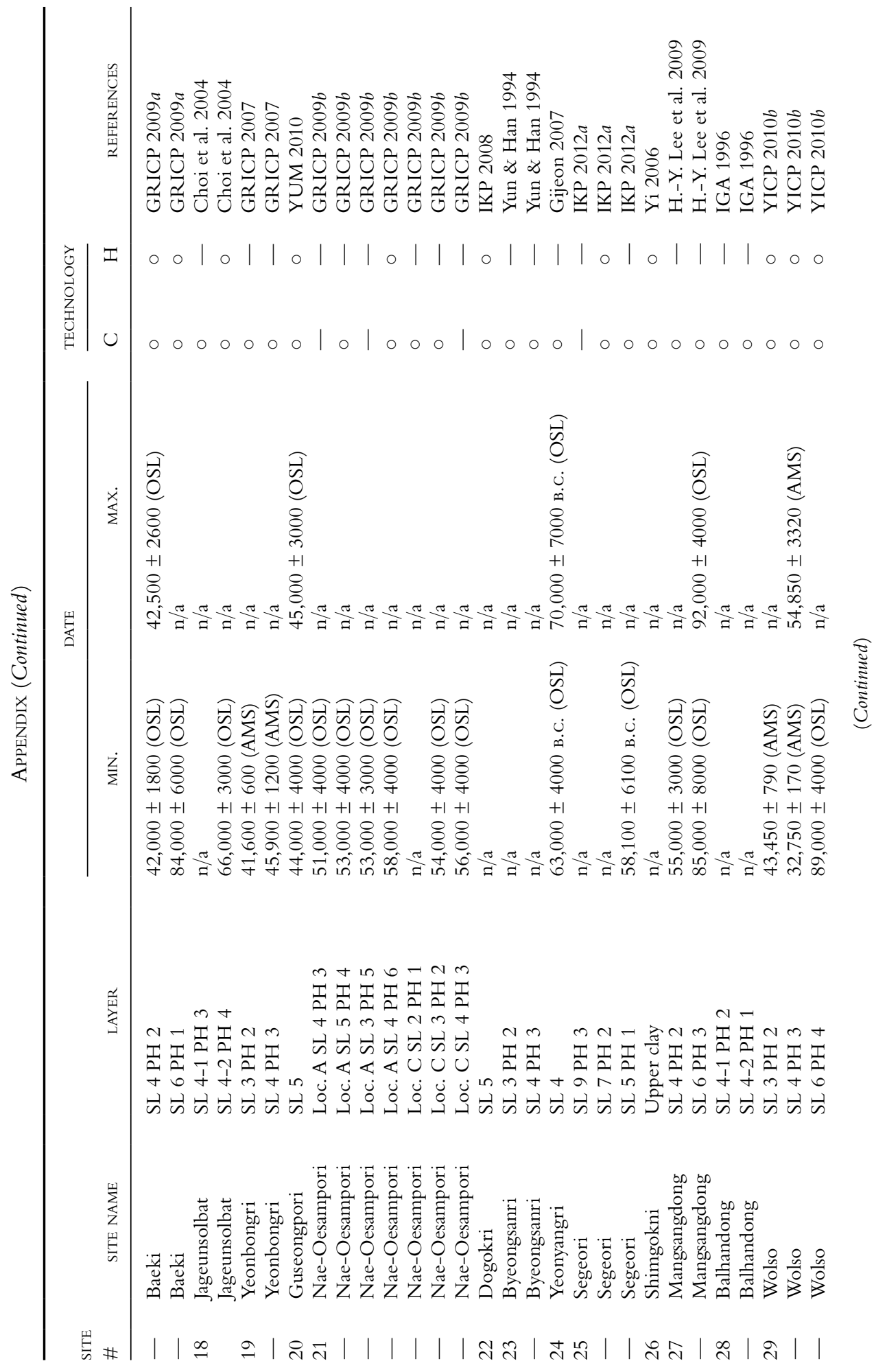




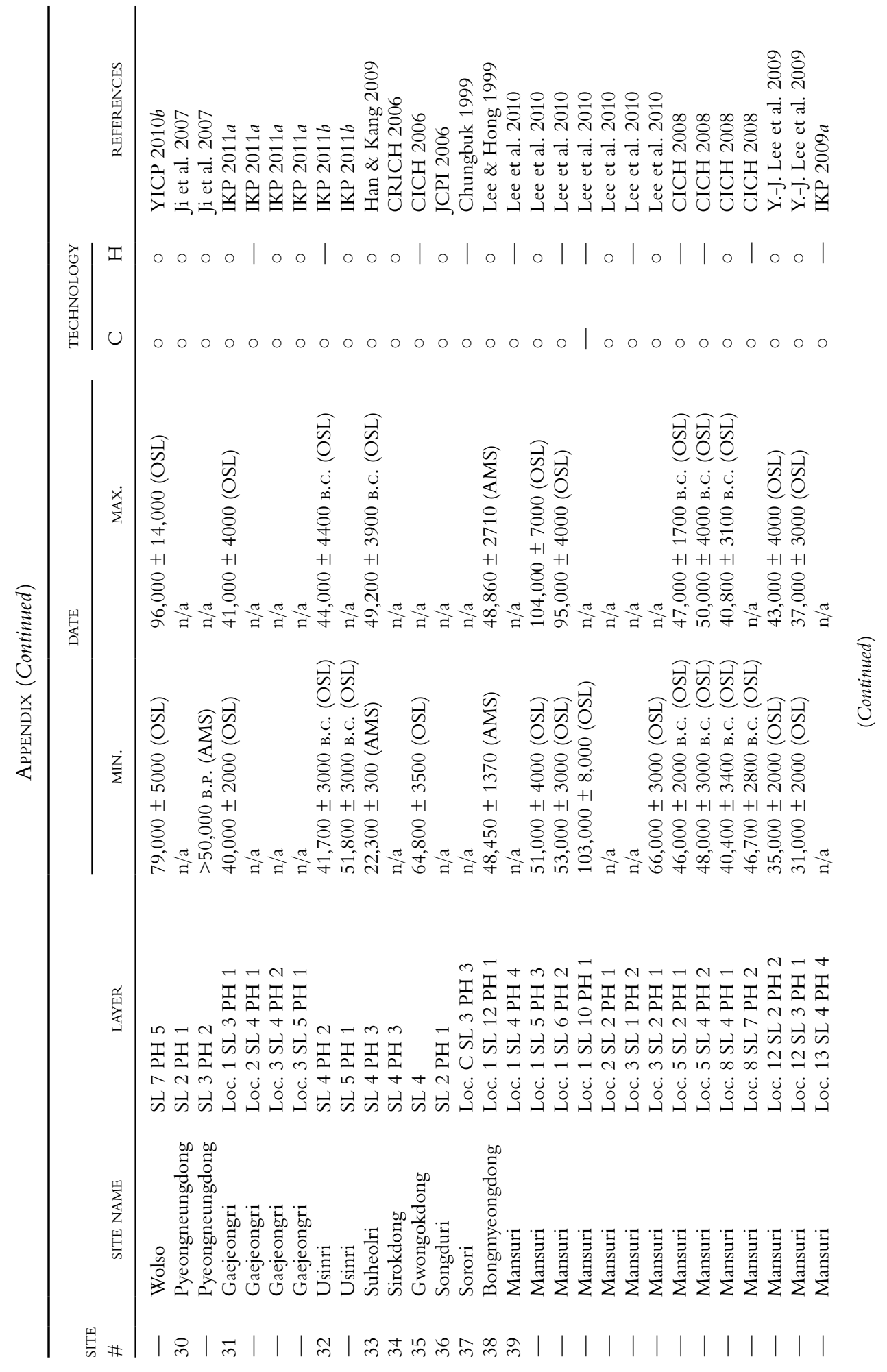




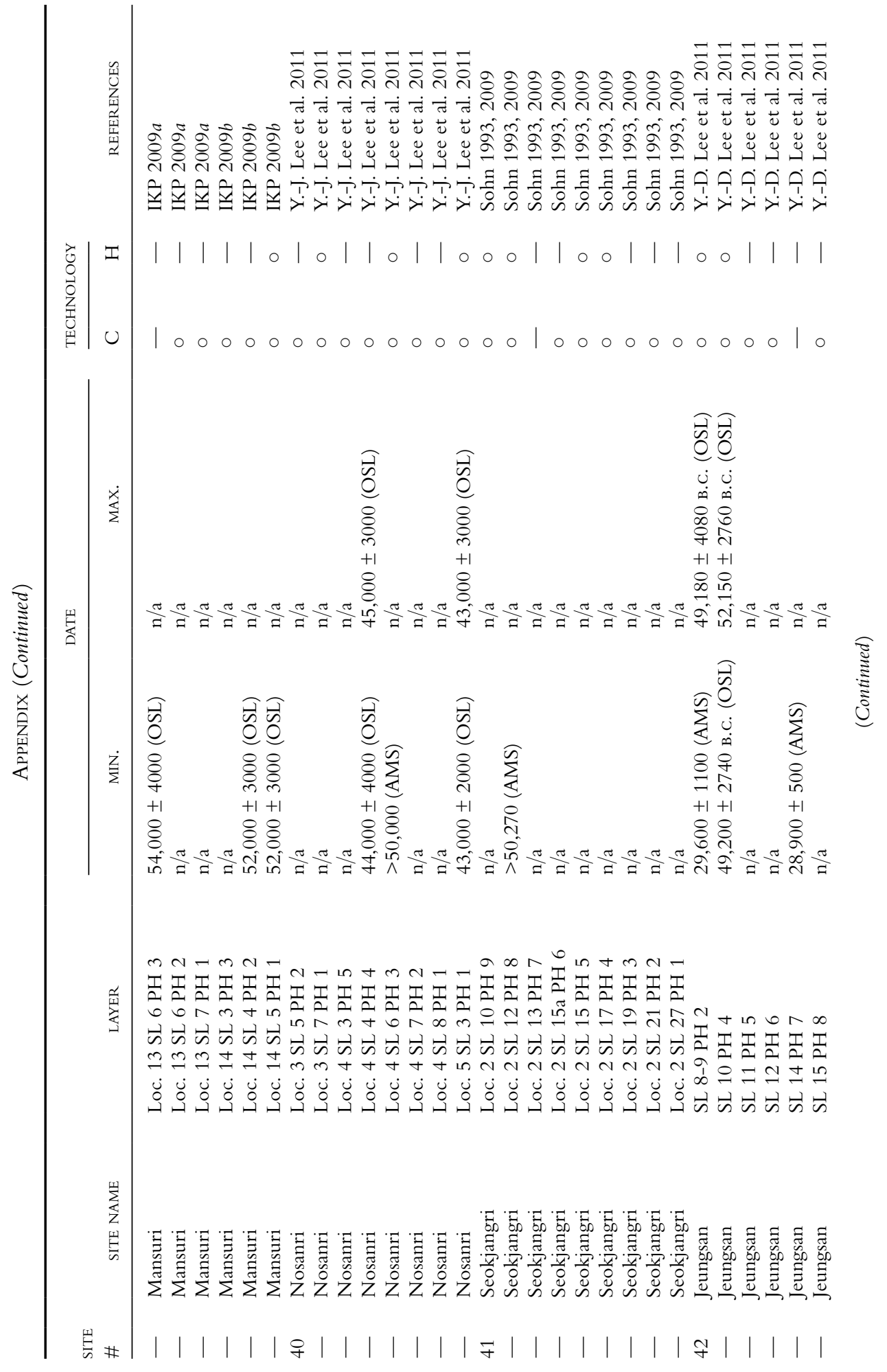




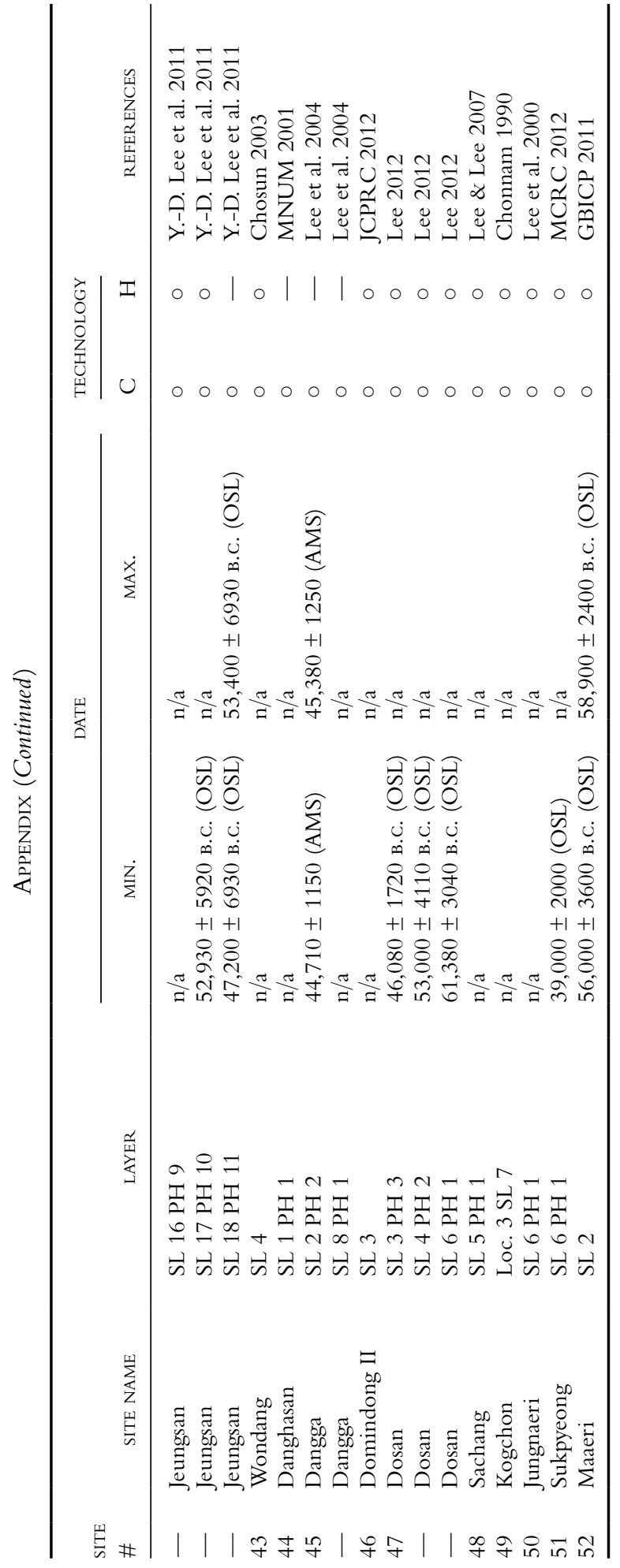




\section{NOTE}

1. Clark's (1969) model is today considered a crude instrument for measuring lithic variability because it does not detect subtle diagnostic variations (Shea 2011:9).

\section{REFERENCES CITED}

Ambrose, Stanley H.

2001 Palaeolithic technology and human evolution. Science 291(5509) : 1748-1753. doi: 10.1126/ science.1059487.

Ao, Hong, Mark J. Dekkers, Qi Wei, Xiaoke Qiang, and Guoqiao Xiao

2013 New evidence for early presence of hominids in North China. Scientific Reports 3. Available at: http://www.nature.com/srep/2013/130815/srep02403/full/srep02403.html.

Bae, Christopher J., and Kidong Bae

2012 The nature of the Early to Late Palaeolithic transition in Korea: Current perspectives. Quaternary International $281: 26-35$.

BAE, K. D., AND J. W. KOH

1993 Report of Excavation of the Chongokni Palaeolithic Site for 1992. Seoul: Department of Cultural Anthropology, Hanyang University (in Korean).

Bae, K. D., C. M. Lee, S. M. Jeong, K. R. Kim, and K. H. Sun

2011 The Jangnamgyo Palaeolithic Site, Yeoncheon, Korea. Ansan: Institute of Cultural Properties, Hanyang University (in Korean).

BAE, KIDONG

1983 A study on hand axes from Chongokni Palaeolithic Site in Korea. Korean Antiquity 22:1-23 (in Korean).

1988 The Significance of the Chongokni Stone Industry in the Tradition of Palaeolithic Culture in East Asia. Ph.D. diss. University of California, Berkeley.

1992 Palaeolithic tradition of East Asia: Chongoknian, presence of few bifaces in Palaeolithic stone industries, in Palaeolithic Culture of East Asia: International Symposium of Cultural Properties 1. Seoul: National Research Institute of Cultural Properties.

$2010 a$ Origin and patterns of the Upper Palaeolithic industries in the Korean Peninsula and movement of modern humans in East Asia. Quaternary International 211(1): 103-112.

2010 b Peopling in the Korean Peninsula, in Asian Paleoanthropology: From Africa to China and Beyond: 181-190, ed. Christopher J. Norton and David R. Braun. Dordrecht, The Netherlands: Springer Press.

Bae, Kidong, Christopher J. Bae, and Kiryong Kim

2012 The age of the Palaeolithic hand axes from the Imjin-Hantan River Basins, South Korea. Quaternary International $281: 14-25$.

Bae, Kidong, SeOnbok Yi, Yongwook Yoo, and G. T. Kim

2005 Chuwoli and Kawoli Palaeolithic Sites. Ansan: Institute of Cultural Properties, Hanyang University (in Korean).

Bar-Yosef, Ofer, and Steven L. Kuhn

1999 The big deal about blades: Laminar technologies and human evolution. American Anthropologist $101(2): 322-338$.

Bar-Yosef, Ofer, AND Youping WANG

2012 Palaeolithic archaeology in China. Annual Review of Anthropology $41: 319-335$.

Brantingham, P. J., X. Gao, D. B. Madsen, R. L. Bettinger, and R. G. Elston

2004 The Initial Upper Palaeolithic at Shuidonggou, Northwestern China, in The Early Upper Palaeolithic beyond Western Europe: 223-241, ed. P. Jeffrey Brantingham, Steven L. Kuhn, and Kristopher W. Kerry. Berkeley: University of California Press.

Buvit, IAN, AND Karisa Terry

2011 Current topics in Siberian Palaeolithic prehistory: Land use, mobility, and technological organization in the Transbaikal, in Hand axes in the Imjin Basin: Diversity and Variability in the East Asian Palaeolithic: 219-254, ed. Seonbok Yi. Seoul: Seoul National University Press. 
Cho, B. K., B. H. Jeon, B. J. Heo, And H. S. Jeong

2010 Singok-ri Site, Gimpo: The Excavation Report of the Cultural Sites at Singok-ri for Construction of an Apartment Bulding in District 3 of Singok, Gimpo. Seoul: Korea Cultural Heritage Foundation (in Korean).

Choi, B., S. An, And H. Ryu

2004 The Hahwagye-ri Palaeolithic and Mesolithic Site (III), Hongcheon. Chuncheon: Institute of Gangwon Archaeology (in Korean).

Choi, M. J.

1994 Palaeolithic Culture in Korea. Seoul: Jipmoondang (in Korean).

CHOI, S.-Y., AND Y.-J. KIM

2008 Galdun Palaeolithic Site, Chonchon. Chuncheon: Gangwon Research Institute of Cultural Properties (in Korean).

Choi, Seung-Yup

2010 A Study on the Palaeolithic Culture in Gangwon Province, Korea. Seoul: Seokyung Press (in Korean).

\section{Chonnam National University Museum}

1990 Research Reports on the Excavation of Cultural Relics in the Area Submerged by the Ju-Am Dam VII. Gwangju: Chonnam National University Museum (in Korean).

Chosun University Museum

2003 Majeon, Gundong, Wondang, and Sudong Sites in Yeonggwang County, Korea. Gwangju: Chosun University Museum (in Korean).

Chung, Young-Wha

1983 Excavation of Chongok-ni Site-Pit, -S1 W2, TR・E, S1 W0. Korean Antiquity 23:1-34 (in Korean).

1992 Palaeolithic in Chongokni, in Palaeolithic Culture of East Asia: International Symposium of Cultural Properties 1. Seoul: National Research Institute of Cultural Properties (in Korean).

Chungbuk National University Museum

1999 Sorori Palaeolithic Site, Cheongju. Cheongju: Chungbuk National University Museum (in Korean).

CiCH (Central Institute of Cultural Heritage)

2006 Gwongok-dong Site, Asan. Seoul: Central Institute of Cultural Heritage.

2008 Mansu-ri Palaeolithic Site-Loc. 5, 6, 7, 8, Cheongwon. Seoul: Central Institute of Cultural Heritage (in Korean).

Clark, Geoffrey

2011 Historical connection and formal convergence in the Lower Palaeolithic of Eurasia, in Hand axes in the Imjin Basin: Diversity and Variability in the East Asian Palaeolithic: 37-82, ed. Seonbok Yi. Seoul: Seoul National University Press.

Clark, Grahame

1969 World Prehistory: A New Outline. Cambridge: Cambridge University Press.

Corvinus, Gudrun

2004 Homo erectus in East and Southeast Asia, and the questions of the age of the species and its association with stone artifacts, with special attention to hand axe-like tools. Quaternary International 117(1): 141-151.

CRich (Chungcheong Research Institute of Cultural Heritage)

2006 Sirok-dong Site, Asan. Gongju: Chungcheong Research Institute of Cultural Heritage (in Korean).

Danhara, Tohoru, K. D. Bae, T. Okada, Kazuto Matsufuji, and S. H. Hwang

2002 What is the real age of the Chongokni Palaeolithic site?, in Palaeolithic Archaeology in Northeast Asia: 77-116, ed. D. Bae and J. C. Lee. Seoul: Yeoncheon County and Institute of Cultural Properties.

DENNELL, ROBIN

2009 The Palaeolithic Settlement of Asia. New York: Cambridge University Press.

Derevianko, A. P.

2010 Three scenarios of the Middle to Upper Palaeolithic transition: Scenario 1: The Middle to Upper Palaeolithic transition in Northern Asia. Archaeology, Ethnology and Anthropology of Eurasia 38(3):2-32. 
Dolitsky, Alexander B., Robert E. Ackerman, Jean S. Aigner, Alan L. Bryan, Robin Dennell, R. Dale Guthrie, John F. Hoffecker, David M. Hopkins, José Luis Lanata, and William B. Workman 1985 Siberian Palaeolithic archaeology: Approaches and analytic methods [and comments and replies]. Current Anthropology 26(3):361-378.

Foley, R., AND M. LAHR

2003 On stony ground: Lithic technology, human evolution, and the emergence of culture. Evolutionary Anthropology: Issues, News, and Reviews 12(3): 109-122.

Gamble, Clive

2001 Modes, movement and moderns. Quaternary International 75(1):5-10.

GAO, XING

2011 The nature of Palaeolithic hand axes from China and its implications for Lower Palaeolithic cultural variation, in Hand axes in the Imjin Basin: Diversity and Variability in the East Asian Palaeolithic: 193-217, ed. Seonbok Yi. Seoul: Seoul National University Press.

Gao, Xing, and Christopher Norton

2002 A critique of the Chinese Middle Palaeolithic. Antiquity 76(292):397-412.

GBiCP (Gyeongsang Bukdo Institute of Cultural Properties)

2011 Maae-ri Palaeolithic Site, Andong. Youngchon: GBICP (in Korean).

Gibbon, Ryan J., Darryl E. Granger, Kathleen Kuman, and Timothy C. Partridge

2009 Early Acheulean technology in the Rietputs Formation, South Africa, dated with cosmogenic nuclides. Journal of Human Evolution 56(2) : 152-160.

Gijeon Institute of Cultural Properties

2007 Yeonyangri Palaeolithic Site, Yeoju. Suwon: Gijeon Institute of Cultural Properties (in Korean).

GRicP (Gangwon Research Institute of Cultural Properties)

2007 The Yeonbong-ri Palaeolithic Site, Hongchen. Chuncheon: GRICP (in Korean).

2009a The Excavation Report on the Baeki, Dolturgury, Songjung sites, Hongchen. Chuncheon: GRICP (in Korean).

2009 b The Nae-Oesampori Palaeolithic Site. Chuncheon: GRICP (in Korean).

Gyeonggi Institute of Cultural Properties

2011 The Wadongri Site (Locality III), Paju. Suwon: Gyeonggi Institute of Cultural Properties (in Korean).

HaN, C. G., AND B. G. KANG

2009 Suheol-ri Site, Jiksan. Gongju: Chuncheong Research Institute of Cultural Heritage (in Korean).

Hou Yamei, Richard Potts, Yuan Baoyin, Guo Zhengtang, Alan Deino, Wang Wei, Jennifer Clark, Xie Guangmao, and Huang Weiwen

2000 Mid-Pleistocene Acheulean-like stone technology of the Bose basin, South China. Science 287(5458) : 1622-1626.

HuANG, W.

1989 Bifaces in China. Human Evolution 4(1): 87-92.

HudSON, MARK J.

2005 For the people, by the people: Postwar Japanese archaeology and the Early Palaeolithic hoax. Anthropological Science 113(2): 131-139.

Hwang, Y. H.

1970 A Study of Myun Mok-Dong Upper Palaeolithic Stone Implements. The Journal of Kyunghee History $2: 15-28$ (in Korean).

1983 Research by Kyunghee University (excavation report), in Chongokni: Excavation Report: 333-451. Seoul: Institute of Cultural Properties (in Korean).

IA (Institute of Archaeology)

1969 The stone tools of Gumumoru. The Journal of Archaeology and Ethnography 1:18-23, 27-28 (in Korean).

ICPH (Institute of Cultural Properties, Hanyang University)

2001 The Chongokni Palaeolithic Site: Report of Test-pit Excavation, 2000-2001. Ansan: Institute of Cultural Properties, Hanyang University (in Korean).

2007 The Report for Chongokni Cultural Heritage. Ansan: Institute of Cultural Properties, Hanyang University (in Korean). 
IGA (Institute of Gangwon Archaeology)

1996 Balhandong Palaeolithic Site, Donghai City. Chuncheon: IGA (in Korean).

IкAwa-Sмiтн, Fumiko

1982 Co-traditions in Japanese Archaeology. World Archaeology 13(3) : 296-309.

IKP (Institute of Korean Prehistory)

2008 Report on the Excavation of Dogokri Palaeolithic Site, Yangpyeong. Cheongju: IKP (in Korean).

2009a Report on the Excavation of Mansu-ri Palaeolithic Site (Loc. 11, 13). Cheongju: IKP (in Korean).

2009 Report on the Excavation of Mansu-ri Palaeolithic Site (Loc. 14). Cheongju: IKP (in Korean).

2011 a Report on the Excavation of Gaejeong-ri Palaeolithic Site, Anseong. Cheongju: IKP (in Korean).

$2011 b$ Report on the Excavation Usin-ri Palaeolithic Site, Cheonan. Cheongju: IKP (in Korean).

2012a Report on the Excavation of Gomyeong-dong Segoeri Palaeolithic Site, Jecheon. Cheongju: IKP (in Korean).

$2012 b$ Report on the Excavation of Loc. 4, 5, 7-1 at Unjeong Palaeolithic Site, Paju I. Cheongju: IKP (in Korean).

2012c Report on the Excavation of Loc. 34, 35, 36-1, 36-4 at Unjeong Palaeolithic Site, Paju II. Cheongju: IKP (in Korean).

2012d Report on the Excavation of Loc. 36-5, 25, 26, 29 at Unjeong Palaeolithic Site, Paju III. Cheongju: IKP (in Korean).

JANG, YONG-JUN

2007 A Study on Technique and Chronology of Upper Palaeolithic Age in Korea. Seoul: Hakyoun Press (in Korean).

JCPI (Jungwon Cultural Properties Institute)

2006 Jinchon Songduri Palaeolithic Site I. Cheongju: JCPI (in Korean).

JCPRC (Jeonnam Cultural Property Research Center)

2012 Report on the Excavation of Do Min Dong, Sang Ya Site. Naju: JCPRC (in Korean).

Ji, H. B., H.-Y. Lee, C.-H. Lee, Y. S. Choi, And N. R. Lee

2007 Pyoungreung-dong Palaeolithic Site. Chuncheon: Gangwon Research Institute of Cultural Properties (in Korean).

KCHF (Korea Cultural Heritage Foundation)

2011 The Excavation Report of the Cultural Sites at Janggi-dong for Construction of a District of Janggi in Hangang New Town, Gimpo. Seoul: KCHF (in Korean).

KIM, G. T., AND Y. S. Song

2009 The Excavation Report of Deogi-dong Palaeolithic Site, Goyang. Suwon: Gyeonggi Cultural Foundation and Gijeon Institute of Cultural Properties (in Korean).

Kim, J. C., G. Duller, H. Roberts, A. Wintle, Y. Lee, and S. B. Yi

2010 Re-evaluation of the chronology of the Palaeolithic site at Jeongokri, Korea, using OSL and TT-OSL signals from quartz. Quaternary Geochronology 5(2-3):365-370.

KIM, S. T.

2012 The Study of Korean Palaeolithic Assemblages. Seoul: Seokyung Press (in Korean).

KIM, WON-YONG

1964 New discoveries on Palaeolithic China. Journal of Korean Historical Association 25:1-15 (in Korean).

1986 A new view on Korea's pre-historic culture: In the context of pre-historic culture of Northeast Asia. Asia Culture $1: 5-13$ (in Korean).

1993 Korea among ancient cultures of Northeast Asia. Mahan Baekje Culture 13:7-12.

Kim, Won-Yong, And Kidong BaE

1983 Research by Seoul University (excavation report), in Chongokni: Excavation Report: 3-173. Seoul: Institute of Cultural Properties (in Korean).

Kim, Won-Yong, And Young-Wha Chung

1978 Preliminary report of Acheulean hand axes at Chongok-ri. Jindan Hakbo 46/47:5-56 (in Korean).

KNUM (Kangwon National University Museum)

1989 Sangmuryongri: Report on the Excavation of Paro Flooded Area. Chuncheon: KNUM (in Korean).

KrimH (Korea Research Institute of Military Heritage)

2010 a Jeongok-ri Palaeolithic Site Yeoncheon, Gyeonggi Province, Korea. Seoul: KRIMH (in Korean).

2010 b Tanhyeon-dong Palaeolithic Site, Goyang, Gyeonggi Province, Korea. Seoul: KRIMH (in Korean). 
2011 Jeongok-ri Palaeolithic Site Yeoncheon, Gyeonggi Province, Korea: Road Construction Site of the Jung 1-2. Seoul: Korea Research Institute of Military Heritage.

2012 Excavation report of Gawol-ri, Jeokseong-myeon, Paju-si, Gyeonni-do, Korea. Seoul: KRIMH (in Korean).

LEE, G.

2012 Characteristics of Palaeolithic industries in southwestern Korea during MIS 3 and MIS 2. Quaternary International 248:12-21.

Lee, G., M. N. Choi, ANd E. J. Kim

2000 Suncheon Jungnae-ri Site. Gwangju: Chosun University Museum (in Korean).

LEe, HeOn-Jong

2002 Evolution of Palaeolithic technology in the Korean Peninsula, in Palaeolithic Culture in Korea: 85-106, ed. Y. J. Park. Seoul: Yonsei University Press (in Korean).

LeE, H.-J., S. H. Rho, AND H.-Y. LeE

2004 Report on Excavation of the Dangga Site and Chongokri Site, Naju. Mokpo: Mokpo National University Museum (in Korean).

Lee, H.-Y., Y. S. Choi, And N. R. LeE

2009 Mangsangdong Palaeolithic Site, Donghae. Chuncheon: Gangwon Research Institute of Cultural Properties (in Korean).

Lee, Hyeong Woo

2001 The Palaeolithic industries in Korea: Chronology and related new find-spots, in $A$ Very Remote Period Indeed: Papers on the Palaeolithic Presented to Derek Roe: 133-137, ed. Sarah Milliken and Jill Cook. Oxford: Oxbow Books.

2006 A Metrical Analysis of Palaeolithic Hand axes in Korea: Identification for Shape Consistency. Korea Journal 46:188-211.

2011 Implication of the bilateral symmetry on hand axes in Korea. Social Science Studies 35(2):277316 (in Korean).

$2013 a$ Current observations of the Early Late Palaeolithic in Korea. Quaternary International $316: 45-58$.

$2013 b$ The persistence of Mode 1 technology in the Korean Late Palaeolithic. PLoS ONE 8(5) : e64999.

LeE, Y. C., AND H.-Y. LeE

2007 Report on the Excavation of the Site at Sachang, Hwasoon. Damyang: Honam Cultural Property Research Center (in Korean).

LeE, Y.-D., E. Y. Song, AND K. J. JANG

2011 Jeungsan Palaeolithic Site, Gochang. Damyang: Honam Cultural Property Research Center (in Korean).

LeE, Yung-Jo

1984 Chronology, in An Essay on Korean History: The Archaeology of Korea: 367-414. Seoul: National Institute of Korean History (in Korean).

LeE, Yung-Jo, And Mi-Young Hong

1999 A Summary Report on the Excavation of Locality at Bongmyeong-dong Site, Cheongju. Cheongju: Chungbuk National University Museum (in Korean).

LeE, Y.-J., S. W. Lee, J. H. An, M. K. Kang, And Y. Kaoru

2009 Report on the Excavation of Mansu-ri Palaeolithic Site (Loc. 12), Cheongwon. Cheongju: Institute of Korean Prehistory (in Korean).

2010 Report on the Excavation of Mansu-ri Palaeolithic Site (Loc. 1, 2, 3), Cheongwon. Cheongju: Institute of Korean Prehistory (in Korean).

LeE, Y.-J., S. W. LeE, AND Y. KaORU

2011 Report on the Excavation of Nosan-ri Palaeolithic Site (Localities 3, 4, 5), Cheongwon. Cheongju: Institute of Korean Prehistory (in Korean).

Lycett, S. J., AND C. J. BAE

2010 The Movius Line controversy: The state of the debate. World Archaeology 42(4):521-544.

Lycett, S. J., AND J.A.J. Gowlett

2008 On questions surrounding the Acheulean "tradition." World Archaeology 40(3) : 295-315.

Lycett, S. J., AND C. J. Norton

2010 A demographic model for Palaeolithic technological evolution: The case of East Asia and the Movius Line. Quaternary International 211(1-2):55-65. 
LyCETt, STEPHEN J.

2009 Are Victoria West cores “proto-Levallois”? A phylogenetic assessment. Journal of Human Evolution 56(2): 175-191.

Lycett, Stephen J., and Noreen von Cramon-Taubadel

2008 Acheulean variability and hominin dispersals: A model-bound approach. Journal of Archaeological Science 35(3) : 553-562.

2011 "Most beautiful and most wonderful": Those endless stone tool forms. Journal of Evolutionary Psychology 9(2): 143-171.

Matsufuji, Kazuto

2011 When were the earliest hominin migrations to the Japanese islands?, in Asian Paleoanthropology: From Africa to China and Beyond: 191-200, ed. Christopher J. Norton and David R. Braun. Dordrecht, The Netherlands: Springer Press.

MCRC (Mahan Culture Research Center)

2012 Report on the Excavation of the Doan-ri, Sukpyeong Site III, Boseong. Suncheon: Mahan Culture Research Center (in Korean).

Mizoguchi, KojI

2006 Self-identification in the modern and post-modern world and archaeological research: A case study from Japan, in Archaeology of Asia: 55-73, ed. M. Stark. Malden: Oxford; Victoria: Blackwell Publishing Ltd.

MNUM (Mokpo National University Museum)

2001 Report on the Excavation of Jangnyeon-ri Danghasan Site, Hampyeong. Mokpo: Mokpo National University Museum (in Korean).

MOLIT (Ministry of LAND, Infrastructure, ANd Transport)

2010 River Management Geographical Information System. Sejong City: MOLIT. Available at:www. river.go.kr/koreamaptest/default.aspx.

Morgan, Christopher, loukas Barton, Mingjie Yi, Robert L. Bettinger, Xing Gao, and Fei Peng

2014 Redating Shuidonggou Locality 1 and implications for the Initial Upper Palaeolithic in East Asia. Radiocarbon 56(1): 165-179.

MORISAKI, KazUKI

2012 The evolution of lithic technology and human behavior from MIS 3 to MIS 2 in the Japanese Upper Palaeolithic. Quaternary International 248:56-69.

Movius, Hallam L.

1948 The Lower Palaeolithic cultures of Southern and Eastern Asia. Transactions of the American Philosophical Society 38(4):329-420.

NeLSON, SARAH

1986 Korean interpretations of Korean archaeology. Asian Perspectives 27(2) :185-191.

Norton, C. J., K. D. Bae, J.W.K. Harris, and H. LeE

2006 Middle Pleistocene hand axes from the Korean Peninsula. Journal of Human Evolution 51(5) : 527-536.

Norton, Christopher, and Kidong Bae

2009 Erratum to "The Movius Line sensu lato (Norton et al., 2006) further assessed and defined" JH Evol. 55 (2008) 1148-1150. Journal of Human Evolution 57(3) :331-334.

Norton, Christopher, Xing Gao, and Xingwu Feng

2009 The East Asian Middle Palaeolithic reexamined, in Sourcebook of Palaeolithic Transitions: 245-254, ed. Marta Camps and Parth Chauhan. New York: Springer.

NRicP (National Research Institute of Cultural Properties)

1992 Palaeolithic Culture of East Asia: International Symposium of Cultural Properties 1. Seoul: NRICP (in Korean).

1999 Kumpari Palaeolithic Site Report of Excavations in 1989-1992. Seoul: NRICP (in Korean).

O’Brien, Michael J., and R. Lee Lyman

2000 Applying Evolutionary Archaeology: A Systematic Approach. New York: Springer.

O’Brien, Michael, and Stephen Shennan

2010 Issues in anthropological studies of innovation, in Innovation in Cultural Systems: Contributions from Evolutionary Anthropology: 3-17, ed. Michael O'Brien and Stephen Shennan. Cambridge, MA: MIT Press. 
Ohel, Milla Y., D. K. Bhattacharya, F. Bordes, Daniel Cahen, P. Callow, Desmond Collins, Paul R. Katz, Karl J. Narr, M. H. Newcomer, R. S. Pappu, Derek A. Roe, Ronald Singer, and J. J. WYMER

1979 The Clactonian: An independent complex or an integral part of the Acheulean? [and comments and reply]. Current Anthropology 20(4):685-726.

PAi, Hyung IL

2000 Constructing "Korean" Origins: A Critical Review of Archaeology, Historiography, and Racial Myth in Korean State-Formation Theories. Cambridge, MA: Harvard University Asia Center.

Pappu, S., Y. Gunnell, K. Akhilesh, R. Braucher, M. Taieb, F. Demory, and N. Thouveny

2011 Early Pleistocene presence of Acheulian hominins in south India. Science 331(6024) :15961599.

PARK, Young-Chul

$1992 a$ The Palaeolithic of Korea: Current observations and their chronology. Journal of Korean Archaeological Society 28:5-130 (in Korean).

$1992 b$ Patterns and chronology of the Palaeolithic stone industries in Korea, in Palaeolithic Culture of East Asia: International Symposium of Cultural Properties 1. Seoul: National Research Institute of Cultural Properties (in Korean).

Peng Fei, Gao Xing, Wang Huimin, Chen FuYou, Liu DeCheng, and Pei ShuWen

2012 An engraved artifact from Shuidonggou, an Early Late Palaeolithic site in Northwest China. Chinese Science Bulletin 57(35): 4594-4599.

Petraglia, Michael, and Ceri Shipton

2008 Large cutting tool variation west and east of the Movius Line. Journal of Human Evolution 55(6) : 962-966.

2009 Erratum to "Large cutting tool variation west and east of the Movius Line"JH Evol. 55 (2008) 962-966. Journal of Human Evolution 57(3):326-330.

Powell, Adam, Stephen J. Shennan, and Mark G. Thomas

2010 Demography and variation in the accumulation of culturally inherited skills, in Innovation in Cultural Systems: 137-160, ed. M. O’Brien and S. Shennan. Cambridge, MA: MIT Press.

Qu, Tongli, Ofer Bar-Yosef, Youping Wang, and Xiaohong Wu

2013 The Chinese Upper Palaeolithic: Geography, chronology, and techno-typology. Journal of Archaeological Research 21(1): 1-73.

RicP (Research Institute of Cultural Properties)

1983 Chongokni. Seoul: Research Institute of Cultural Properties (in Korean).

ROE, DEREK

1968 British Lower and Middle Palaeolithic hand axe groups. Proceedings of the Prehistoric Society $34: 1-82$

Schick, Kathy, and Desmond Clark

2003 Biface technological development and variability in the Acheulean industrial complex in the Middle Awash region of the Afar Rift, Ethiopia, in Multiple Approaches to the Study of Bifacial Technologies: 1-30, ed. Marie Soressi and Harold Dibble. Philadelphia: Museum of Archaeology and Anthropology, University of Pennsylvania.

Seong, Chuntaek

2002 The relevance of the Middle Palaeolithic in Korea: A critical review. Journal of Korean Archaeological Society 46:5-28 (in Korean).

2003 Principles of Darwinian Evolutionary Archaeology. Journal of the Honam Archaeological Society $17: 113-133$ (in Korean).

2006 A comparative and evolutionary approach to the Korean Palaeolithic assemblages. Journal of Korean Ancient Historical Society 51:5-42 (in Korean).

2009 Emergence of a blade industry and evolution of Late Palaeolithic technology in the Republic of Korea. Journal of Anthropological Research 65(3): 417-451.

2011 Evaluating radiocarbon dates and Late Palaeolithic chronology in Korea. Artic Anthropology 48(1) : 93-112.

2012 The Palaeolithic Age, in An Essay on Korean Archaeology: 27-50. Seoul: Sahui Pyungron, Korean Archeological Society (in Korean).

SHEA, JOHN J.

2011 Homo sapiens is as Homo sapiens was. Current Anthropology 52(1) :1-35. 
SHENNAN, S.

2001 Demography and cultural innovation: A model and its implications for the emergence of modern human culture. Cambridge Archaeological Journal 11(1):5-16.

2009 Pattern and process in cultural evolution; an Introduction, in Pattern and Process in Cultural Evolution: 1-18, ed. Stephen Shennan. Berkeley: University of California Press.

SNUM (Seoul National University Museum)

1989 Chongokni Site-Report of the Excavation of the Chongokni Palaeolithic Site, 1986. Seoul: SNUM (in Korean).

2004 Jangsan-ri: A Lower Palaeolithic Site in Paju, Korea. Seoul: SNUM (in Korean).

SoHn, P. K.

1967 Stratified Palaeolithic cultures newly excavated In Korea. Journal of the Korean Historical Association 35/36:1-25 (in Korean).

1968 Pebble chopping-tool industry of the stratified Palaeolithic cultures of Seokchang-ni, Korea. Journal of Korean History $1: 7-68$ (in Korean).

1969 Surface finds of the Palaeolithic tools in Korea. Journal of the Paeksan Society 7:2-24 (in Korean).

1972 The Korean culture in the Old Stone Age. Paekche Yonku 3:55-72 (in Korean).

1993 Seokjangri Prehistoric Site. Seoul: Dong-A Publication (in Korean).

2002 From history to prehistory, in Palaeolithic Culture in Korea: 9-21, ed. Y. J. Park. Seoul: Yonsei University Press (in Korean).

2009 The Seokchangni Site and the Palaeolithic Culture of Korea. Seoul: Hakyoun Press (in Korean).

Sohn, P. K., B. S. Han, And Y.-J. LeE

1982 The Korean Palaeolithic culture: Research and prospects (dialogue paper). Journal of the Korean Association of Humanities and the Social Sciences 6:150-184 (in Korean).

Trigger, Bruce

1984 Alternative archaeologies: Nationalist, colonialist, imperialist. Man n.s. 19 (3) :355-370.

1986 Prospects for a world archaeology. World Archaeology 18(1) :1-20.

2008 A History of Archaeological Thought, 2nd ed. Cambridge: Cambridge University Press.

Vasil'ev, Sergey A., Yaroslav V. Kuzmin, Lyubov A. Orlova, and Vyacheslav N. Dementiev

2006 Radiocarbon-based chronology of the Palaeolithic in Siberia and its relevance to the peopling of the New World. Radiocarbon 44(2) : 503-530.

WANG, SHEJIANG

2005 Perspectives on Hominid Behaviour and Settlement Patterns: A Story of the Lower Palaeolithic Sites in the Luonan Basin, China. BAR International Series 1406. Oxford: Archaeopress.

Wang, W., S. Lycett, N. von Cramon-Taubadel, J. Jin, and C. J. Bae

2012 Comparison of hand axes from Bose Basin (China) and the Western Acheulean indicates convergence of form, not cognitive differences. PLoS ONE 7(4) : e35804.

White, Mark J.

2000 The Clactonian question: On the interpretation of core-and-flake assemblages in the British Lower Palaeolithic. Journal of World Prehistory 14(1) : 1-63.

Yi, SEONBOK

1989 Northeast Asian Palaeolithic Research. Seoul: Seoul National University Press (in Korean).

1996 Chronostratigraphy of Palaeolithic occurrences in the Imjin Basin. Journal of the Korean Archaeological Society 34:135-160 (in Korean).

2000 For chronology and stratigraphy of the Korean Palaeolithic. Journal of the Korean Archaeological Society 42:1-22 (in Korean).

2002 Aspects of Middie-Upper Palaeolithic transition in Northeast Asia. Seoul Journal of Korean Studies $15: 75-99$.

2006 Excavation Report at Shimgok-ni. Seoul: Seoul National University Museum (in Korean).

2010 Radiocarbon age of the Basalt Plain in the Imjin Basin: Archaeological implications. Journal of the Korean Palaeolithic Society 22:3-20 (in Korean).

2011 Hand axes in the Imjin Basin, in Hand axes in the Imjin Basin: Diversity and Variability in the East Asian Palaeolithic: 3-21, ed. Seonbok Yi. Seoul: Seoul National University Press.

2013 On some "Early Palaeolithic" evidence of Japan. Journal of Korean Palaeolithic Society 26:49-62.

Yi, Seonbor, Yongwook Yoo, and Dongwan Kim

2006 Excavation Report at Jeongok ACF Site and its Vicinity. Seoul: Seoul National University Museum (in Korean). 
2011 Excavation in the Road Construction Site of the Jung 2-5 Line in Jeongok-ri (Chongokni). Seoul: Seoul National University Museum (in Korean).

YiCP (Yemaek Institute of Cultural Properties)

2009 Report on the Excavation of Geodu-ri Site, Chuncheon. Chuncheon: YICP (in Korean).

2010 a Report on the Excavation of Mogok-ri Site, Hongcheon. Chuncheon: YICP (in Korean).

$2010 b$ Report on the Excavation of Wolso Site, Mukhojin-dong, Donghae. Chuncheon: YICP (in Korean).

2011 Report on the Excavation of Seosang-ri Site, Chuncheon. Chuncheon: YICP (in Korean).

Yoo, YONGWOOK

2007 Long-term Changes in the Organization of Lithic Technology: A Case Study from the Imjin-Hantan River Area, Korea. Ph.D. diss. McGill University, Montreal.

2009 A speculation on the temporal horizon of hand axes from the Chongokni Site: A heuristic approach. Journal of Jungbu Archaeological Society 8:5-25 (in Korean).

Yu, T., S. Hwang, S. Kim, and J. Tang

2013 The Excavation Report of the Palaeolithic Site, Mancheon-ri, Chuncheon City. Chuncheon: Seohae Institute of Culture Heritage (in Korean).

YUM (Yonsei University Museum)

2010 Guseongpo Palaeolithic Site. Wonju: YUM (in Korean).

Yun, N. H., AND C. G. HAN

1994 The Byeongsan-ri Palaeolithic Site, Yangpyeon. Seoul: Dankook University Museum (in Korean).

\begin{abstract}
Increasing data from early Korean Palaeolithic assemblages have challenged the validity of traditional paradigms. This article summarizes previous models and addresses recently raised questions regarding the synthesis of early toolkits. Determining chronologies, cultural markers, and regional cultural traits were our primary objectives. The applicability of the traditional Western Palaeolithic chronology (Lower, Middle, Upper) to East Asian contexts has recently been questioned, in conjunction with an effort to identify more discrete chronological changes in East Asia. The discourse related to cultural identities within East Asia has underscored the importance of spatially and temporally differing values. The morphology and metrics of Korean hand axes have not been considered typical Acheulean. In addition, temporal persistence is an issue; it has caused the conventional culture-historical orthodoxy to be questioned. Discourses on expedient lithic reduction and a static lithic sequence have been considered indicative of discrete cultural entities in the Korean Palaeolithic. Oldowan-like simple core and flake assemblages and the sporadic occurrence of hand axe assemblages in East Asia were traditionally regarded to be chronologically and culturally separate entities. The growing body of archaeological data for Korea has allowed analysis of the occupational contemporaneity and cultural subordination and independence of chopping tool and hand axe assemblages. The Korean Early Palaeolithic is not standardized and does not conform to traditional typologies. Consequently, the directional perspectives applied to these assemblages need to be reevaluated. Keywords: Korea, Early Palaeolithic, Oldowan, Acheulean, lithics, tool kits, chronology.
\end{abstract}

